\title{
ARTICLE
}

\section{Reactions of $\boldsymbol{N}$-heterocyclic Carbene-Based Chalcogenoureas with Halogens: A Diverse Range of Outcomes}

Received 00th January 20xx, Accepted 00th January 20xx

DOI: $10.1039 / x 0 x \times 00000 x$

\author{
Marina Saab, ${ }^{\mathrm{a}}$ David J. Nelson, ${ }^{\mathrm{b}}$ Matthew Leech, ${ }^{\mathrm{c}}$ Kevin Lam, ${ }^{\mathrm{c}}$ Steven P. Nolan, ${ }^{\mathrm{d}}$ Fady Nahra*a,e and \\ Kristof Van Hecke*a
}

\begin{abstract}
We have investigated the reactions of chalcogenoureas derived from $N$-heterocyclic carbenes, referred to here as [E(NHC)], with halogens. Depending on the structure of the chalcogenourea and the identity of the halogen, a diverse range of reactivity was observed and a corresponding range of structures were obtained. Cyclic voltammetry was carried out to characterize the oxidation and reduction potentials of these $[\mathrm{E}(\mathrm{NHC})]$ species; selenoureas were found to be easier to oxidize than the corresponding thioureas. In some cases, a correlation was found between the oxidation potential of these compounds and the electronic properties of the corresponding NHC moiety. The reactivity of these chalcogenoureas with different halogenating reagents $\left(\mathrm{Br}_{2}, \mathrm{SO}_{2} \mathrm{Cl}_{2}, \mathrm{I}_{2}\right)$ was then investigated, and products were characterized using $\mathrm{NMR}$ spectroscopy and single-crystal X-ray diffraction. X-ray analyses elucidated the solid-state coordination types of the obtained products, showing that a variety of possible adducts can be obtained. In some cases, we were able to extrapolate a structure/activity correlation to explain the observed trends in reactivity and oxidation potentials.
\end{abstract}

\section{Introduction}

$\mathrm{N}$-heterocyclic carbene (NHC) derivatives of main group elements have attracted considerable attention in recent years. ${ }^{1} \mathrm{NHC}$ ligands are known to stabilize unusual oxidation states and monomeric compounds of main group elements, which are otherwise unstable or oligo- or polymeric. ${ }^{2}$ Chalcogenones (also known as chalcogenoureas), the NHC derivatives of chalcogens $(E=S, S e, T e)$, have been the focus of many recent developments owing to their applications in various fields. ${ }^{3}$ For example, selenoneine, isolated from tuna, has shown strong antioxidant capacity. ${ }^{4}$ Thio- and selenoureas with similar structures to selenoneine have also been shown by Brumaghim and co-workers to inhibit copper-mediated oxidative damage. ${ }^{5}$ Some selenoureas have exhibited inhibitory activity towards lactoperoxidase-catalyzed oxidation and iodination reactions. ${ }^{6}$ More recently, Roy and co-workers showed that suitable designs of thio- and selenoureas could be used to detoxify various organomercurials. ${ }^{7}$

\footnotetext{
a.XStruct, Department of Chemistry, Ghent University, Krijgslaan 281, Building S3, 9000 Ghent, Belgium. Kristof.VanHecke@UGent.be

b. WestCHEM Department of Pure \& Applied Chemistry, University of Strathclyde, 295 Cathedral Street, Glasgow, G1 1XL, Scotland.

c. School of Science, University of Greenwich, Chatham Maritime ME4 4TB, UK.

d. Department of Chemistry, Ghent University, Krijgslaan 281, Building S3, 9000 Ghent, Belgium.

e. VITO (Flemish Institute for Technological Research), Boeretang 200, $2400 \mathrm{Mol}$, Belgium.Fady.Nahra@Vito.be

Electronic Supplementary Information (ESI) available: Experimental sections, NMR spectra of new compounds prepared during this study.

See DOI: $10.1039 / x 0 x \times 00000 x$
}

The dihalogen derivatives of chalcogenones are also of high current interest with their own wide range of applications in coordination, biological, industrial, and materials chemistry as well as in synthetic chemistry as electrophilic group-transfer reagents. ${ }^{8,9}$ For example, dihaloselones can act as oxidizing agents for metal powders, affording ionic metal complexes that feature a variety of geometries and unusual oxidation states. ${ }^{9}$ Both chalcogenones and dihalochalcogenones are excellent precursors for dicationic dichalcogenides $\left(\left[\mathrm{L}_{2} \mathrm{E}_{2}\right]^{2+} ; \mathrm{L}=\right.$ ligand). ${ }^{6,10}$ A broad range of dicationic diselenides of the form $\left[\mathrm{L}_{2} \mathrm{Se}_{2}\right] \mathrm{MX}_{4}$ were accessed via the controlled oxidation of selone complexes of metal halides (i.e., $\left[\mathrm{MX}_{2}(\mathrm{LSe})_{2}\right]$ ) with halogenating agents such as $\mathrm{SOCl}_{2}, \mathrm{Br}_{2}$ or $\mathrm{I}_{2} \cdot{ }^{11}$ The reaction of dihaloselones with elemental tellurium can, depending on the conditions, afford dicationic diselenides or selone coordinated monomeric tellurium tetrahalides. ${ }^{10 a, 12}$ The reduction of dihaloselones to dicationic diselenides in the presence of a strong Lewis acid has been reported. ${ }^{11}$

Our interest lies mainly in the peculiar reactivity of NHC-based chalcogenones $([\mathrm{E}(\mathrm{NHC})])$ in oxidation reactions with halogenating agents. These reactions can follow a variety of pathways depending on the nature of the oxidant, the experimental conditions used and, most importantly, the chalcogenone reactant. To date, most studies in this field have revealed that a variety of products could be obtained, including: (i) T-shaped structural adducts $(X-E-Y)$ by homolytic breakage of the dihalogen $(X-X)$ or interhalogen $(X-Y)$ bond; (ii) chargetransfer (CT) arrangements featuring a linear bond between the donor (chalcogen) $(E=\mathrm{Se}, \mathrm{S})$ and the dihalogen or interhalogen $(\mathrm{E}-\mathrm{X}-\mathrm{Y})$; (iii) dicationic dichalcogenides $\left(\left[\mathrm{L}_{2} \mathrm{E}_{2}\right]^{2+}\right)$ consisting of a chalcogen-chalcogen single bond; and (iv) two-chalcogencoordinated halogen $(\mathrm{I})$ complexes $\left([\mathrm{LE}-\mathrm{X}-\mathrm{EL}]^{+}\right) .{ }^{13}$ Other exciting 
structural features that can be obtained include outer-sphere polyhalides as counteranions to ionic halo-chalcogenone complexes, ${ }^{14}$ which adds further complexity to this oxidation chemistry.

Predicting the outcome or the geometry of the final compounds when reacting these chalcogenoureas with di- or interhalogens is still far from straightforward, though important advancements have been made. ${ }^{8,9}$ Studies have shown that a lower electronegativity difference between the halogen and the chalcogen is directly correlated to a higher probability of affording a linear CT adduct as opposed to the T-shaped adducts. ${ }^{15}$ The stability of the CT product is also associated with the polarizability of the donor atom; consequently, systems with selenium as the donor are more stable than ones with sulfur donors. ${ }^{13 a}$ Regarding T-shaped adducts, there is no decisive report explaining the nature of the bond between the carbon (from the NHC) and chalcogen. However, some reports, such as the work of William and co-workers on accessing selenoamide- $\mathrm{Br}_{2}$ with a T-shaped linkage, ${ }^{16}$ have attempted to tackle this subject. They suggested that these molecules are stable zwitterionic selenium complexes with an aromatic heterocyclic carbene; the $\mathrm{C}$-Se bond is depicted as a single bond, with a positive charge on the aromatic ring and a negative charge on the $\mathrm{SeBr}_{2}$ group. ${ }^{16}$ In contrast, Devillanova and coworkers interpreted the $\mathrm{C}$-Se interaction as a double bond, suggesting that the carbene is stabilized by the $\mathrm{Br}$-Se-Br moiety rather than the backbone (i.e., traditional metal-NHC coordination). ${ }^{13 a-e}$ A systematic investigation of the oxidation behavior using a large sample of NHC-based chalcogenoureas and a variety of oxidants is essential in order to shed light on the role of the carbene moiety in stabilizing the complexes that form. This is required to enable a much better understanding of

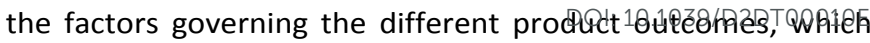
will in turn give us better tools for future predictions.

We have previously reported the synthesis of chalcogenoureas derived from NHCs and their coordination chemistry to transition metals. ${ }^{17}$ We also explored the correlation between the electronic properties (mainly $\pi$-accepting ability ${ }^{18}$ ) of the ligands and the geometry of the complexes in the solid state. In this report, we sought to define and understand the trends in their reactions with different types of oxidizing halogen sources (i.e., $\mathrm{Br}_{2}, \mathrm{I}_{2}$ and $\mathrm{SO}_{2} \mathrm{Cl}_{2}$ ) with the aim of gaining further insight into the role of these $\mathrm{NHC}$ ligands and consequently their influence over reaction outcomes. All new products were characterized by ${ }^{1} \mathrm{H},{ }^{13} \mathrm{C}\left\{{ }^{1} \mathrm{H}\right\}$ and ${ }^{77} \mathrm{Se}\left\{{ }^{1} \mathrm{H}\right\}$ NMR spectroscopy and elemental analysis. Furthermore, the large variety of structural adducts was investigated using single-crystal $\mathrm{X}$-ray diffraction analysis. It should be noted that for several products, multiple single crystals were investigated to confirm the presence of one or several adduct types for the same bulk material. To better understand the redox chemistry of these compounds, cyclic voltammetry analysis was also performed.

\section{Results and Discussion}

All chalcogenoureas $[E(\mathrm{NHC})](E=S$, Se) were synthesized according to our previously reported procedure, via deprotonation of the imidazolium salts using a weak base approach $\left(\mathrm{K}_{2} \mathrm{CO}_{3}\right.$ or $\left.\mathrm{NEt}_{3}\right)$ (Figure 1). ${ }^{17 a}$ All compounds were then characterized using cyclic voltammetry (CV), and their reactivity with $\mathrm{Br}_{2}, \mathrm{I}_{2}$ and $\mathrm{SO}_{2} \mathrm{Cl}_{2}$ was investigated. a)

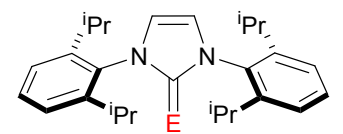

1: [Se(IPr)]

2: [S(IPr)]

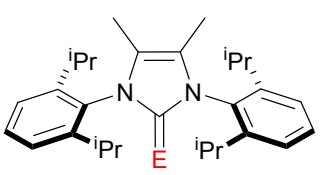

9: [Se(IPrMe $)]$

10: $\left[\mathrm{S}\left(\mathrm{IPr}^{\mathrm{Me}}\right)\right]$

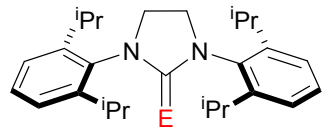

3: [Se(SIPr)]

4: [S(SIPr)]

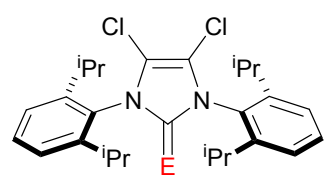

11: $\left[\mathrm{Se}\left(\mathrm{IPr}^{\mathrm{Cl}}\right)\right]$

12: $\left[\mathrm{S}\left(\mathrm{IPr}^{\mathrm{Cl}}\right)\right]$

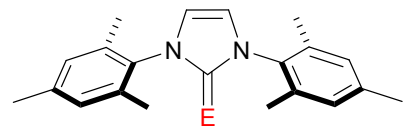

5: [Se(IMes)]

6: [S(IMes)]

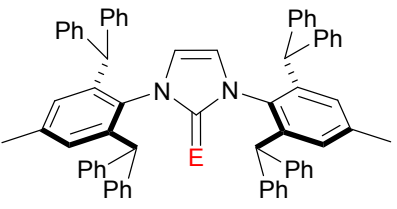

13: [Se(IPr*)]

14: [S(IPr*)]

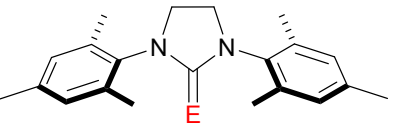

7: [Se(SIMes)]

8: [S(SIMes)]

b)

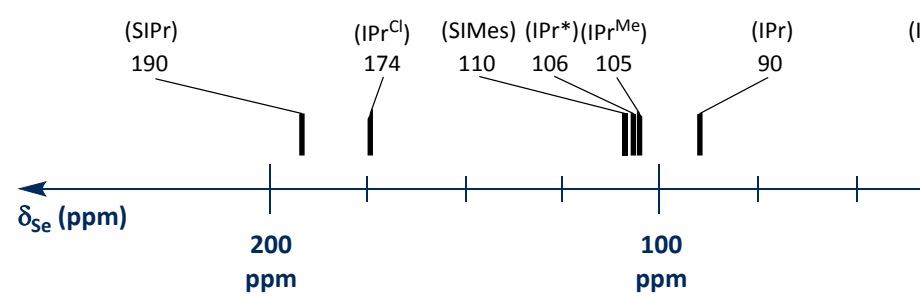

Stronger $\pi$-acceptors

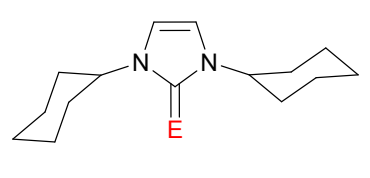

15: [Se(ICy] 16: [S(ICy)]

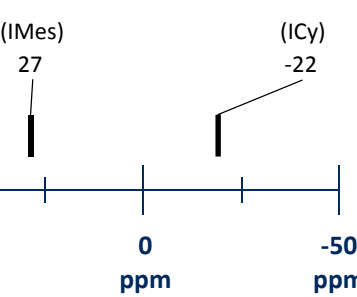

Figure 1. a) Seleno- and thiourea NHCs used in this work. b) The $\pi$-accepting properties of NHCs measured using ${ }^{77}$ Se NMR spectroscopy of the corresponding selenoureas. 


\section{Cyclic voltammetry}

In an attempt to explore the influence of the NHC moiety on the redox potential and to better understand the oxidation behavior of the corresponding chalcogenoureas, CV measurements were performed for all compounds in dichloromethane under dry and oxygen free conditions. The results of these analyses are listed in Table 1.

\begin{tabular}{|c|c|c|c|}
\hline Entry & Compound & Epa vs Fc (V) & Epc vs Fc (V) \\
\hline 1 & {$[\mathrm{Se}(\mathrm{IPr})]$} & 0.52 & -0.36 \\
\hline 2 & {$[\mathrm{Se}\{\mid \mathrm{Mes})]$} & 0.57 & -0.46 \\
\hline 3 & {$\left[\mathrm{Se}\left(\mathrm{IPr} \mathrm{Me}^{\mathrm{Me}}\right)\right]$} & 0.41 & -0.45 \\
\hline 4 & {$\left[\mathrm{Se}\left(\mathrm{IPr}^{\mathrm{C} \mid}\right)\right]$} & 0.76 & -0.17 \\
\hline 5 & [Se(SIPr)] & 0.69 & -0.43 \\
\hline 6 & [Se(SIMes)] & 0.67 & -0.6 \\
\hline 7 & {$\left[\mathrm{Se}\left(\operatorname{IPr}^{*}\right)\right]$} & 0.74 & none \\
\hline 8 & [Se(ICy)] & 0.41 & -0.57 \\
\hline 9 & {$[S(I P r)]$} & 0.77 & -0.23 \\
\hline 10 & [S\{IMes)] & 0.73 & -0.44 \\
\hline 11 & {$\left[\mathrm{~S}\left(\mathrm{IPr} \mathrm{Me}^{\mathrm{Me}}\right)\right]$} & 0.53 & -0.36 \\
\hline 12 & {$\left[\mathrm{~S}\left(\mid \mathrm{Pr}^{\mathrm{Cl}}\right)\right]$} & 0.96 & 0.07 \\
\hline 13 & {$[S(S \mid P r)]$} & 1.09 & -1.16 \\
\hline 14 & [S(SIMes)] & 1.08 & -0.7 \\
\hline 15 & {$[S(\operatorname{IPr} *)]$} & 0.87 & none \\
\hline 16 & {$[S(I C y)]$} & 0.52 & -0.44 \\
\hline
\end{tabular}

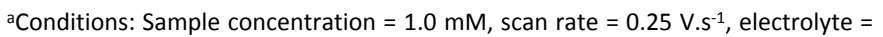
$\left[n \mathrm{Bu}_{4} \mathrm{~N}\right]\left[\mathrm{PF}_{6}\right](0.1 \mathrm{M})$, solvent $=\mathrm{DCM}$, electrode $=$ Glassy carbon.

All chalcogenoureas were oxidized by scanning toward positive potentials, before reversing the scan direction back to the starting potential (Figures 2 and 3). Both [Se(NHC)] and [S(NHC)] adducts showed similar chemically irreversible one-electron oxidation behavior. The peak potential $\left(E_{p a}\right)$ of the oxidation at a scan rate of $0.25 \mathrm{~V} . \mathrm{s}^{-1}$ appears between $0.41 \mathrm{~V}$ and $0.76 \mathrm{~V}$ for [Se(NHC)], and between $0.52 \mathrm{~V}$ and $1.09 \mathrm{~V}$ for [S(NHC)].

In most cases, the compounds undergo an electron transfer (E) followed by a chemical reaction (C), following a typical EC-type mechanism. The reduction of the EC product occurs at much lower potentials $\left(E_{p c}\right)$ than the expected re-reduction of the oxidized chalcogenourea radical cation. Similar observations have previously been made for NHC-based thio- and selenoureas. ${ }^{18-19}$ The initial electron transfer is reported to be followed by a rapid chemical reaction; in this case, the radical cation of the corresponding chalcogenourea reacts with its unoxidized counterpart to form a dimer radical cation $\left[\{\mathrm{E}(\mathrm{NHC})\}_{2}\right]^{\cdot+}$. $^{19 \mathrm{c}}$ The reaction of the initial radical cation with itself to form the dicationic dimer, $\left[\{\mathrm{E}(\mathrm{NHC})\}_{2}\right]^{2+}$, has also been proposed for similar compounds, and cannot be excluded (Scheme 1). ${ }^{19 a-b}$ In the reverse scan, the reduction of the dimeric species is observed for all compounds $\left(E_{p c}\right)$, except for IPr*based ones.

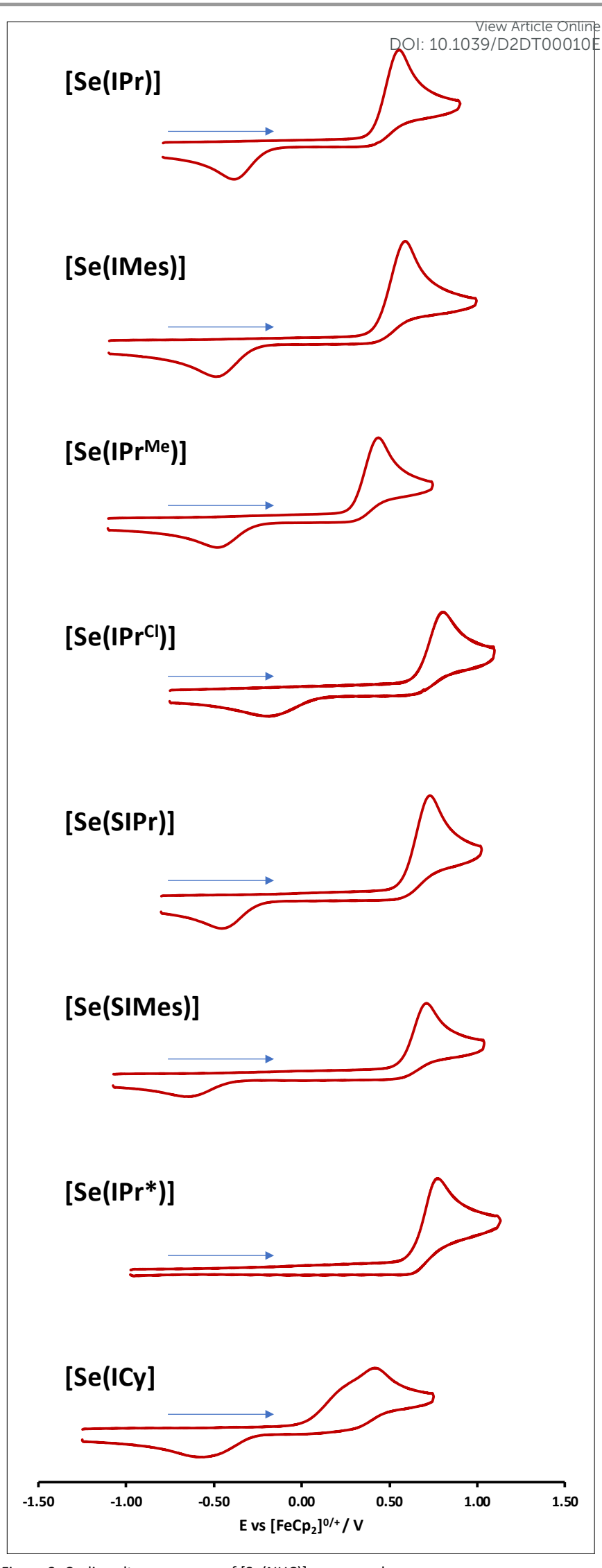

Figure 2. Cyclic voltammograms of [Se(NHC)] compounds. 


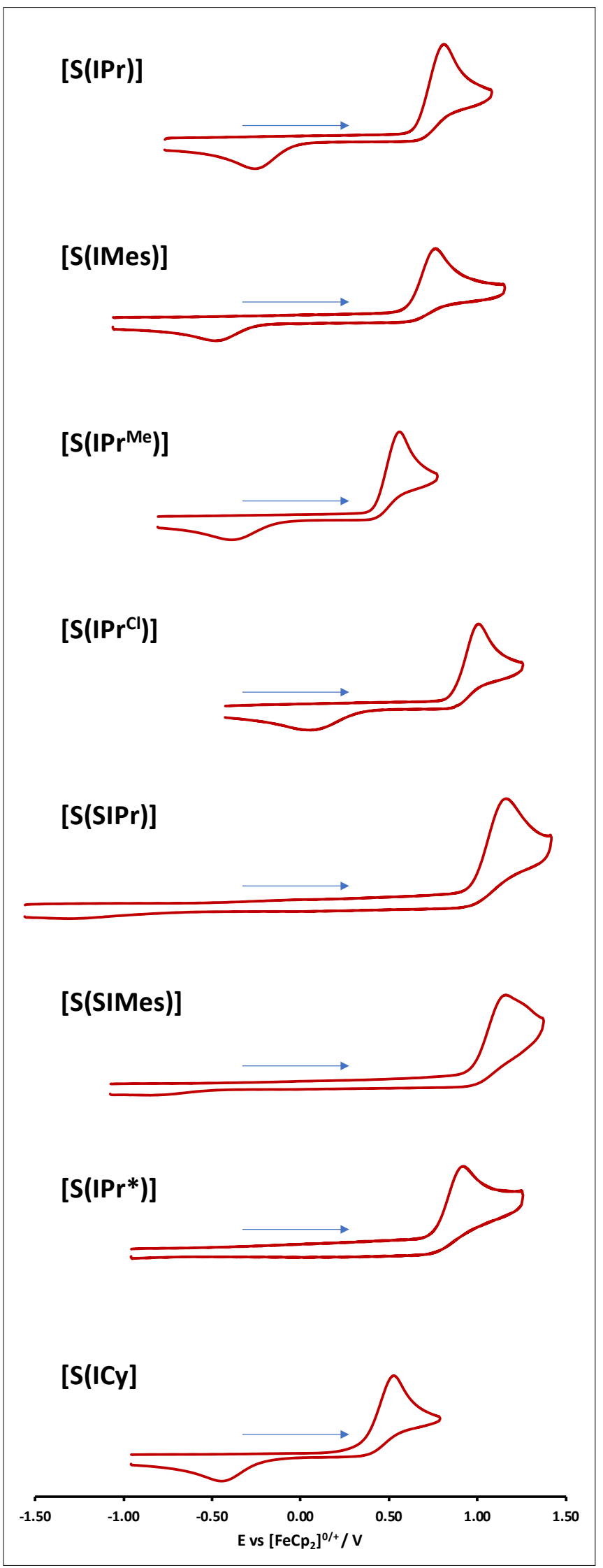

Figure 3. Cyclic voltammograms of $[\mathrm{S}(\mathrm{NHC})]$ compounds.

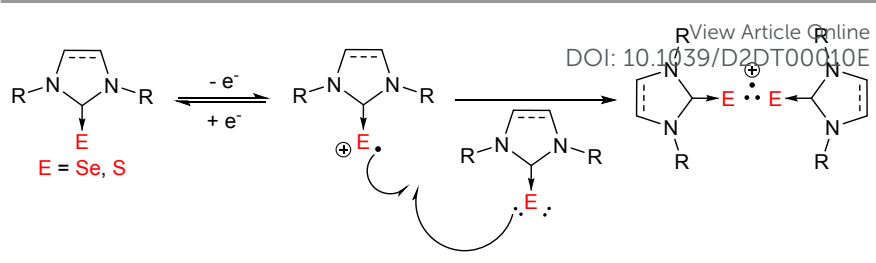

Scheme 1. Possible EC mechanism of the electrochemical oxidation of $[\mathrm{E}(\mathrm{NHC})]$ adducts and subsequent dimer formation.

$\mathrm{CV}$ data clearly indicates that the selenourea adducts are easier to oxidize than their thiourea counterparts, which is consistent with previous observations. ${ }^{20}$ With regard to the influence of the NHC moiety on the oxidation potential of the chalcogenoureas, some trends can be identified. Thio- and selenoureas bearing NHCs with a saturated backbone, such as SIPr and SIMes, are much more difficult to oxidize than their unsaturated counterparts, such as IPr and IMes (Table 1, entries 5-6 vs 1-2 and 13-14 vs 9-10). The unsaturated backbones in IPr and IMes serve to decrease the oxidation potentials of the corresponding chalcogenoureas, presumably due to the increased resonance stabilization of the oxidized radical species.

When comparing $\mathrm{IPr}^{\mathrm{Me}}$ - and $\mathrm{IPr}^{\mathrm{Cl}}$-based thio- and selenoureas to the parent IPr-adducts, lower oxidation potentials are observed with IPrMe, whilst higher oxidation potentials are obtained with $\mathrm{IPr}^{\mathrm{Cl}}$. ICy is the only $\mathrm{N}$-substituted alkyl NHC in the series and gave the lowest oxidation potentials with both selenium and sulfur. Unfortunately, these results cannot easily be quantitatively correlated to the electronic properties of the corresponding NHCs. However, it can be deduced that substituents on the imidazole ring directly influence the oxidation potential of the chalcogenoureas by stabilizing or destabilizing the oxidized radical species. Electron-donating alkyl substituents on the backbone (e.g., $\mathrm{IPr}^{\mathrm{Me}}$ ) or on the nitrogen atom (e.g., ICy) of the imidazole ring have a stabilizing effect, while electron-withdrawing groups on the backbone (e.g., $\mathrm{IPr}^{\mathrm{Cl}}$ ) have the opposite effect.

A direct scanning in the negative cathodic direction failed to show a reduction peak for most of the compounds, except for $[\mathrm{S}(\mathrm{ICY})]$ and $\left[\mathrm{S}\left(\mathrm{IPr}^{*}\right)\right]$ (Figures S1 and S2). For both compounds, two similar successive reduction waves were observed at -1.49 $\mathrm{V}$ and $-1.68 \mathrm{~V}$. Previous studies on triazolylidene-based selenoureas showed similar reduction waves, albeit at much lower potentials $(-2.4 \mathrm{~V}$ to $-2.7 \mathrm{~V})$, with only one compound displaying two successive reduction waves (a trifluoromethylphenyl-substituted triazolyl-idene). ${ }^{19 b} \mathrm{As}$ it is the case here with $[\mathrm{S}(\mathrm{ICY})]$ and $[\mathrm{S}(\mathrm{IPr} *)]$, the chemically irreversible first reductions of all triazolyl-selenoureas were attributed to an EC mechanism, which forms a new (unidentified) species. In accordance with these findings, the two irreversible reductions observed in each of the $[\mathrm{S}(\mathrm{ICY})]$ and $\left[\mathrm{S}\left(\mathrm{IPr} \mathrm{Pr}^{*}\right)\right]$ cases, can be attributed to a possible ECE mechanism (two-electron reduction process separated by a chemical transformation); a re-oxidation wave for the new species was also observed, in both cases, at $-0.7 \mathrm{~V}$.

Overall, the redox potentials in Table 1 already provide a general idea of how these NHC-based chalcogenones will 
behave in oxidation reactions involving different halogenating agents. Chlorinating agents such as $\mathrm{Cl}_{2}$ or $\mathrm{SO}_{2} \mathrm{Cl}_{2}\left(\mathrm{Cl}_{2} / \mathrm{Cl}^{-} ; \mathrm{E}^{\circ}=\right.$ $+1.36 \mathrm{~V})$ would be expected to succeed in oxidizing most of the $[\mathrm{E}(\mathrm{NHC})]$ compounds described in this report, presumably leading to T-shaped or other equivalent ionic structures. In contrast, iodinating agents, such as $\mathrm{I}_{2}\left(\mathrm{I}_{2} / \mathrm{I}^{-} ; \mathrm{E}^{\circ}=+0.54 \mathrm{~V}\right)$, would not be expected to oxidize any of the compounds, thus affording exclusively CT-type arrangements. The use of a brominating agent, such as $\mathrm{Br}_{2}\left(\mathrm{Br}_{2} / \mathrm{Br}^{-} ; \mathrm{E}^{\circ}=+1.09 \mathrm{~V}\right)$, is definitely the most interesting approach to explore, as it can unpredictably lead to either CT- or T-shaped structures, making it likely that the reaction outcomes are very substratedependent for the most part.

\section{Reactions of Chalcogenoureas with Bromine}

As summarized in Scheme 2, all of the seleno- and thiourea NHCs were treated with 1.2 equiv. of bromine in dichloromethane, resulting in the complete conversion of each substrate to new orange-colored compounds. In order to discern the various structural geometries of the obtained products, single crystals were grown by vapor diffusion of pentane into a saturated solution of these products in dichloromethane.

$$
\text { (1.2 equiv.) }
$$

Scheme 2. Possible products from the reaction of $[\mathrm{E}(\mathrm{NHC})]$ with $\mathrm{Br}_{2}$.

\section{[Se(NHC)] reactions with $\mathrm{Br}_{2}$}

Single-crystal X-ray diffraction analysis of all seleniumcontaining products formed after bromination showed the cleavage of the bromine-bromine bond with concomitant oxidation of the selenone moiety (Figure 49. With fhee exception of SIPr- and IPrCl-selenoureas, all compounds afforded T-shaped adducts trans-[ $\left.\mathrm{SeBr}_{2}(\mathrm{NHC})\right]$ after crystallization, with an almost linear $\mathrm{Br}$-Se-Br arrangement. However, the crystallization of the products from the reactions of $[\mathrm{Se}(\mathrm{SIPr})]$ and $\left[\mathrm{Se}\left(\mathrm{IPr}^{\mathrm{Cl}}\right)\right]$ with bromine afforded L-shaped cationic adducts with tribromide counterions, i.e., $[\mathrm{SeBr}(\mathrm{NHC})]\left[\mathrm{Br}_{3}\right]$. The latter reactions were repeated with strict $1: 1$ stoichiometry and multiple single crystals were investigated from each batch to identify whether one or several products were present; each time the same result was obtained. This unusual structural motif has been observed previously from the reactions of NHC-based selenoureas and thioureas with iodine, but it is much less common when bromine is used. Only one example has been previously reported for the reaction of 2-benzimidazolethione with $\mathrm{Br}_{2} \cdot{ }^{21}$ We suspect that this type of structure only occurs in the solid-state, after crystallization, and that in solution (or in the bulk powder prior to crystallization) typical T-shaped adducts are obtained. This hypothesis is based on the fact that the powder X-ray diffraction ( $\mathrm{pXRD}$ ) pattern of the bulk material from the reaction of $\mathrm{Se}(\mathrm{SIPr})$ with bromine, prior to crystallization, did not match the pXRD pattern simulated from the single crystal XRD data of $[\mathrm{SeBr}(\mathrm{SIPr})] \mathrm{Br}_{3}$. Our previous observations, when investigating the coordination behavior of [Se(NHC)] compounds with group 11 transition metal halides $(\mathrm{Cu}, \mathrm{Ag}, \mathrm{Au})$, have also highlighted this phenomenon, as rearranged structures were obtained exclusively in the solidstate after crystallization. ${ }^{17}$ As before, this trend seemed to be correlated to the $\pi$-accepting ability of the NHC moiety (Scheme 1 ); selenoureas bearing NHCs with stronger $\pi$-accepting ability $\left(\delta_{\mathrm{se}}>174 \mathrm{ppm}\right.$, such as SIPr and $\left.\mathrm{IPr}^{\mathrm{Cl}}\right)$ would afford rearranged cationic structures while ones with weaker $\pi$-accepting ability would give the neutral monomeric adducts. Table 2 illustrates a selection of bond lengths and angles from these structures.

Table 2. Selected bond lengths $(\AA)$ and angles $\left(^{\circ}\right)$ for the dibromoselenoureas

\begin{tabular}{|c|c|c|c|c|c|c|}
\hline Structures & $\mathrm{C}_{1}-\mathrm{Se}_{1}$ & $\mathrm{Se}_{1}-\mathrm{Br}_{1}$ & $\mathrm{Se}_{1}-\mathrm{Br}_{2}$ & $\mathrm{C}_{1}-\mathrm{Se}_{1}-\mathrm{Br}_{1}$ & $\mathrm{C}_{1}-\mathrm{Se}_{1}-\mathrm{Br}_{2}$ & $\mathrm{Br}_{1}-\mathrm{Se}_{1}-\mathrm{Br}_{2}$ \\
\hline$\left[\mathrm{SeBr}_{2}(\mathrm{IPr})\right]$ & $1.900(4)$ & $2.5047(6)$ & $2.6560(6)$ & $96.84(10)$ & $88.60(10)$ & $174.57(2)$ \\
\hline$[\mathrm{SeBr}(\mathrm{SIPr})] \mathrm{Br}_{3}$ & $1.920(3)$ & $2.3055(4)$ & - & $105.44(9)$ & - & - \\
\hline$\left[\mathrm{SeBr}_{2}(\mathrm{IMes})\right]$ & $1.900(3)$ & $2.5641(4)$ & $2.5641(4)$ & $93.88(1)$ & $93.88(1)$ & $172.23(2)$ \\
\hline$\left[\mathrm{SeBr}_{2}(\mathrm{SIMes})\right]$ & $1.939(10)$ & $2.5586(8)$ & $2.5586(8)$ & 91.75(3) & $91.75(3)$ & $176.51(6)$ \\
\hline$\left[\mathrm{SeBr}_{2}\left(\mathrm{IPr}^{\mathrm{Me}}\right)\right]$ & $1.906(2)$ & $2.5717(4)$ & $2.5953(4)$ & $96.36(7)$ & $89.97(7)$ & $173.65(2)$ \\
\hline$\left[\mathrm{SeBr}\left(\mid \operatorname{Pr}^{\mathrm{Cl}}\right)\right] \mathrm{Br}_{3}$ & $1.880(4)$ & $2.3508(7)$ & - & $102.46(12)$ & - & - \\
\hline$\left[\mathrm{SeBr}_{2}(\mathrm{ICy})\right]$ & $1.894(5)$ & $2.7151(7)$ & $2.4849(8)$ & $83.89(14)$ & $91.07(14)$ & $174.89(3)$ \\
\hline
\end{tabular}




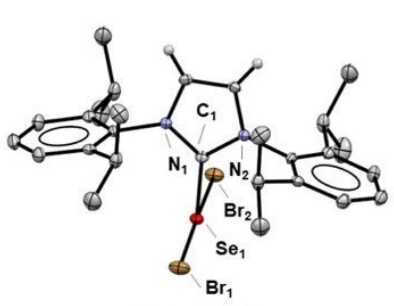

[SeBr $($ IPr)]

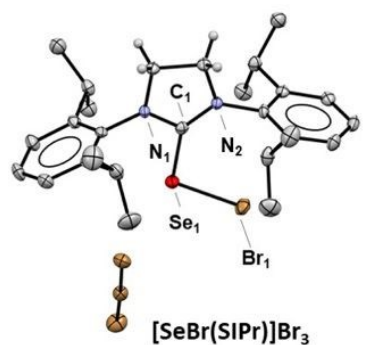

[SeBr(SIPr)]Br

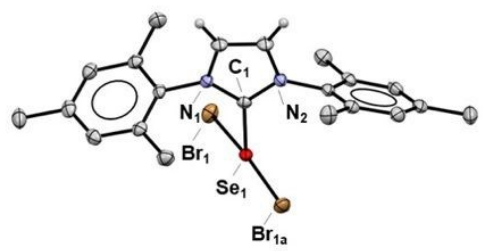

[SeBr (IMes)]

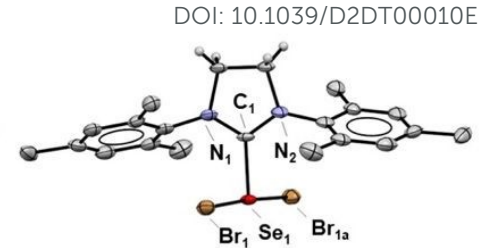

[SeBr ${ }_{2}$ (SIMes)]

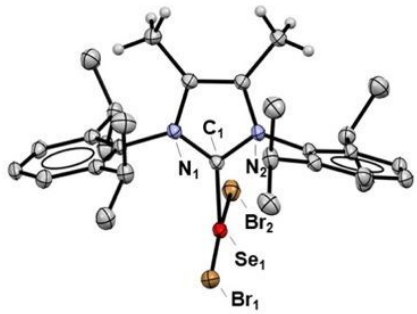

$\left[\mathrm{SeBr}_{2}\left(\operatorname{IPr}^{\mathrm{Me}}\right)\right]$

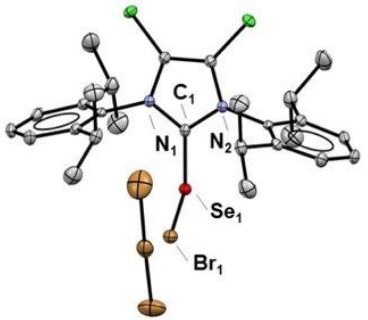

$\left[\mathrm{SeBr}\left(\operatorname{Pr}^{\mathrm{C}}\right)\right] \mathrm{Br}_{3}$

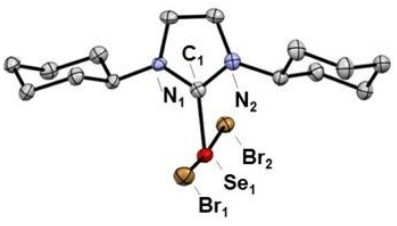

$\left[\mathrm{SeBr}_{2}(\mathrm{ICy})\right]$

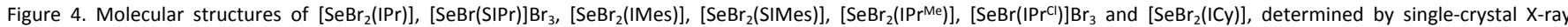
diffraction analysis. Most hydrogen atoms and all solvent molecules are omitted for clarity. Thermal displacement ellipsoids are shown at the $50 \%$ probability level.

The Se-Br bond in all structures is significantly shorter (by $35 \%$ ) than the sum of the van der Waals radii for selenium and bromine (ca. $3.85 \AA$ A ), indicating a strong Se-Br bond and allowing the delocalization of the Se charge density. For $\mathrm{T}$ shaped structures, the $\mathrm{Br}_{1}-\mathrm{Se}_{-} \mathrm{Br}_{2}$ group is linear with angles ranging between $172.23(2)^{\circ}$ and $176.51(6)^{\circ}$, and with both Se$\mathrm{Br}$ bonds of all structures almost perpendicular to the Se- $\mathrm{C}_{1}$ bond. In the $\left[\mathrm{SeBr}_{2}(\mathrm{IPr})\right]$ and $\left[\mathrm{SeBr}_{2}(\mathrm{ICY})\right]$ structures, the bond lengths $\mathrm{Br}_{1}-\mathrm{Se}_{1}$ and $\mathrm{Se}_{1}-\mathrm{Br}_{2}$ differ for each compound (by $0.1513(6)$ and $0.2302(8) \AA$, for $\left[\mathrm{SeBr}_{2}(\operatorname{IPr})\right]$ and $\left[\mathrm{SeBr}_{2}(\mathrm{ICy})\right]$, respectively), which is accompanied by variances in the $\mathrm{Br}_{1}-\mathrm{Se}_{1}$ $\mathrm{C}_{1}$ and $\mathrm{Br}_{2}-\mathrm{Se}_{1}-\mathrm{C}_{1}$ angles (by $8.24(10)^{\circ}$ and $7.18(14)^{\circ}$, for $\left[\mathrm{SeBr}_{2}(\mathrm{IPr})\right]$ and $\left[\mathrm{SeBr}_{2}(\mathrm{ICy})\right]$, respectively) such that the longest $\mathrm{Se}-\mathrm{Br}$ bond corresponds with the smallest $\mathrm{Br}-\mathrm{Se}-\mathrm{C}$ angle. This may be explained by weak intra- and inter-molecular interactions between the $\mathrm{Br}$ and $\mathrm{H}$ atoms, as shown for [SeBr$\left.{ }_{2}(\mathrm{ICy})\right]$ in Figure 5 (dashed lines).

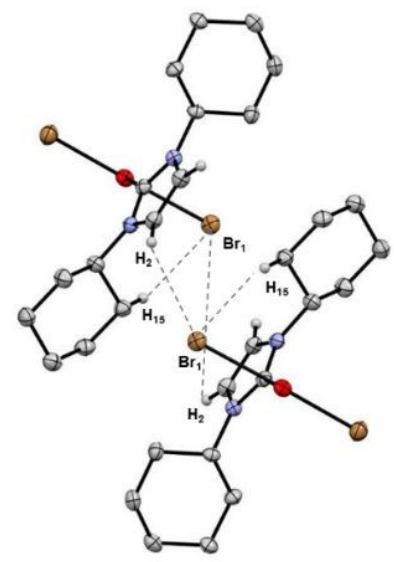

Figure 5. Partial view of the crystal packing of $\left[\mathrm{SeBr}_{2}(\mathrm{ICY})\right]$ showing the intramolecular bond interaction $\mathrm{Br}_{1}-\mathrm{-}-\mathrm{H}_{15}(3.06 \AA)$ and intermolecular bond interaction $\mathrm{Br}_{1}-\mathrm{-}-\mathrm{H}_{2}$ (3.06 Å).
A significant lengthening of the $C_{1}$-Se bond (1.88-1.94 $\AA$ ) is also observed for all the new products compared to the initial $\mathrm{C}_{1}$-Se bond ( $c a .1 .83 \AA$ ) of the starting selenoureas [Se(NHC)], which would be consistent with a decrease in bond order. A similar increase in length is observed for $\mathrm{C}_{1}$-Se bonds upon complexation of [Se(NHC)] to group 11 transition metal halides, such as gold chloride (ca. $1.88 \AA$ A). Dibromo-selenoureas derived from NHCs bearing a saturated backbone exhibit the longest $\mathrm{C}_{1^{-}}$ Se bonds (1.920(3) and 1.939(10) $\AA$, for [Se(SIPr)] and [Se(SIMes)], respectively). This trend is accompanied by the shortening of the $\mathrm{C}_{1}-\mathrm{N}_{1}$ and $\mathrm{C}_{1}-\mathrm{N}_{2}$ bonds in all of the new products as compared to the initial [Se(NHC)] compounds. Collectively, these observations indicate an increase in the double bond character for both $\mathrm{C}_{1}-\mathrm{N}$ bonds, along with a decrease for that of $\mathrm{C}_{1}$-Se. As shown in Scheme 3, $\left[\mathrm{SeBr}_{2}(\mathrm{NHC})\right]$ can be represented by two resonance structures (I and III); however, based on observations, a better representation of the actual structure may lie somewhere in the middle (hybrid form II). For unsaturated NHCs, conjugation of the backbone double bond with the nitrogen lone pair diminishes the electron contribution of the latter to the Se moiety (form Ilb); this does not happen with derivates of saturated NHCs (form Ila), thus contributing to a more pronounced $\mathrm{C}_{1}$-Se single bond character in these compounds and consequently a longer $\mathrm{C}_{1}$-Se bond, as is the case for SIPr- and SIMes-based dibromo-selenoureas. 

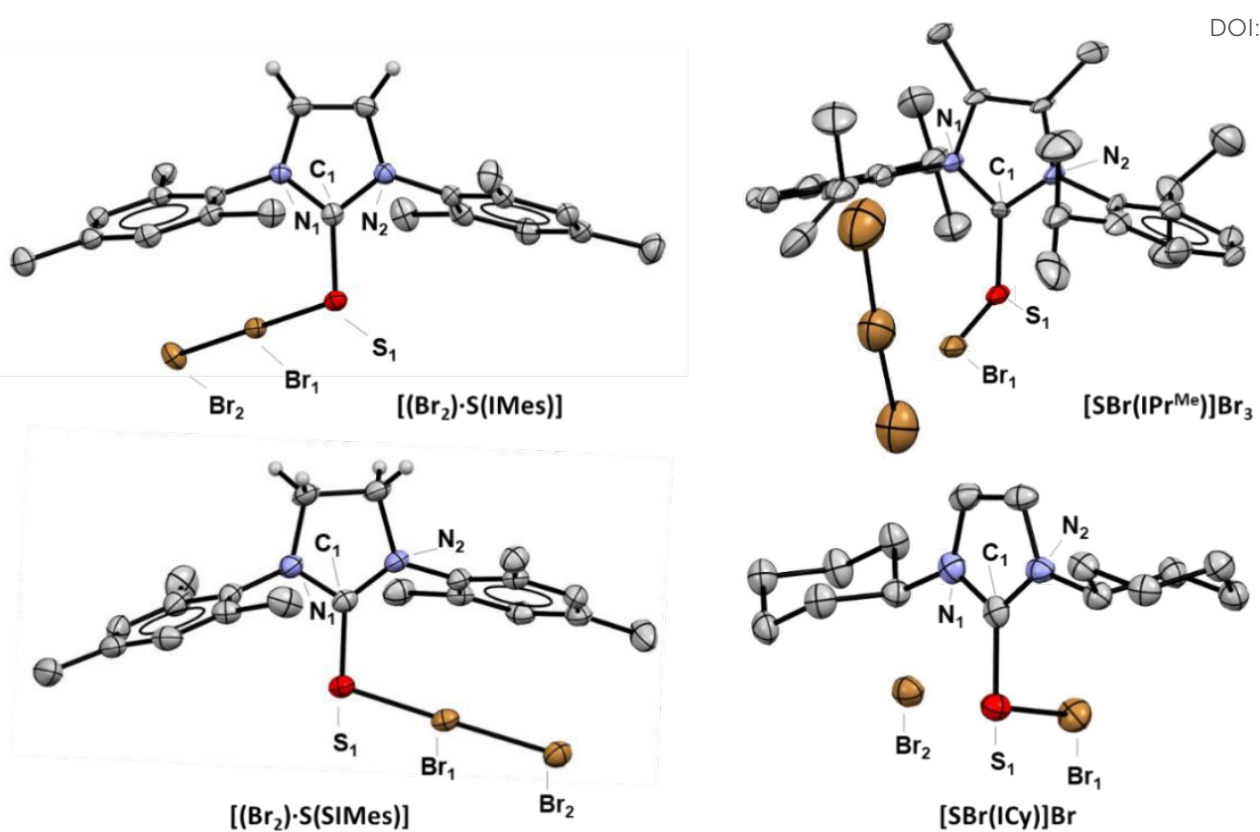

Figure 6. Molecular structures of [( $\left.\left.\mathrm{Br}_{2}\right) \cdot \mathrm{S}(\mathrm{IMes})\right],\left[\left(\mathrm{Br}_{2}\right) \cdot \mathrm{S}(\mathrm{SIMes})\right],\left[\mathrm{SBr}\left(\mathrm{IPrMe}^{\mathrm{Me}}\right)\right] \mathrm{Br}_{3}$ and $[\mathrm{SBr}(\mathrm{ICy})] \mathrm{Br}$, as determined by single-crystal X-ray diffraction analysis. Most hydrogen atoms and solvent molecules are omitted for clarity. Thermal displacement ellipsoids are shown at the $50 \%$ probability level.

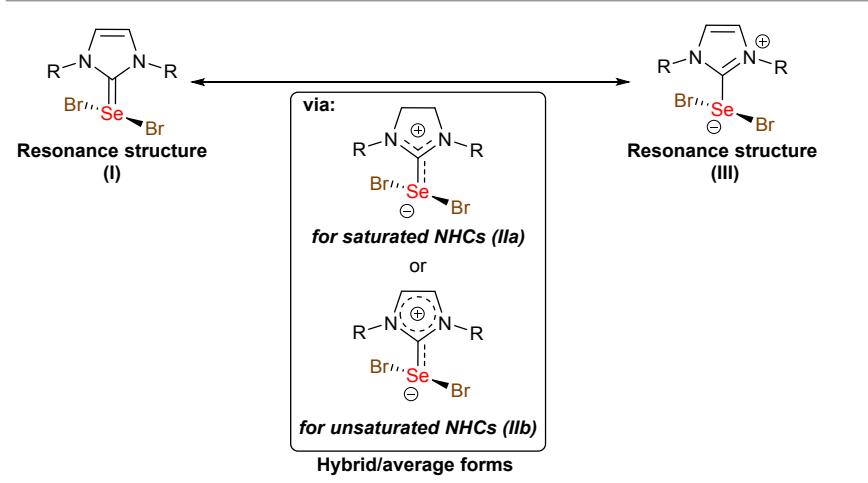

Scheme 3. $\left[\mathrm{SeBr}_{2}(\mathrm{NHC})\right]$ resonance structures (I and III) and resonance hybrid forms (IIa and $\mathrm{Ilb}$ ), showing electron flow in saturated vs unsaturated NHCs.

\section{[S(NHC)] reactions with $\mathrm{Br}_{2}$}

The reactions of $[\mathrm{S}(\mathrm{NHC})]$ compounds with bromine led to products of more than one structural motif (Figure 6). The product of the reaction of [S(SIMes)] and bromine, after crystallization, displayed a CT-type structure $\left(\left[\left(\mathrm{Br}_{2}\right) \cdot \mathrm{S}(\mathrm{SIMes})\right]\right)$ wherein the sulfur atom is coordinated to dibromine with a $\mathrm{S}$ $\mathrm{Br}-\mathrm{Br}$ angle of $178.65(3)^{\circ}$. To a certain extent, this was expected from the high oxidation potential of $[\mathrm{S}(\mathrm{SIMes})]\left(\mathrm{E}_{\mathrm{pa}}=1.08 \mathrm{~V}\right.$, Table 1). A similar outcome was observed from the reaction of [S(IMes)] with bromine. [S(IMes)] has a lower oxidation potential than [S(SIMes)] $\left(E_{p a}=0.73 \mathrm{~V}\right.$, Table 1), placing it in a similar range to that for some of the selenoureas (i.e., [Se( $\left(\mathrm{Pr}^{\mathrm{Cl}}\right)$ ] and $\left.\left[\mathrm{Se}\left(\mathrm{IPr}^{*}\right)\right]\right)$; it was therefore expected to afford T- or Lshaped products derived from the oxidation of the thiourea. However, since only the CT complex $\left[\left(\mathrm{Br}_{2}\right) \cdot \mathrm{S}(\mathrm{IMes})\right]$ was observed, other factors are surely at play; the difference in electronegativity between the halogen and the chalcogen is one possibility. It has been reported that upon decreasing the difference in electronegativity between the halogen and the chalcogen (e.g., $\Delta \mathrm{EN}_{\mathrm{Br} / \mathrm{s}}=0.38$ vs $\Delta \mathrm{EN}_{\mathrm{Br} / \mathrm{se}}=0.41$ ), $\mathrm{CT}$ adducts are formed more easily than hypervalent chalcogen adducts when reacting chalcogen donors with dihalogens or interhalogens. ${ }^{13 a, 15}$

The reactions of [S(IPrMe $)]$ and [S(ICy)] with bromine gave, after crystallization, hypervalent thiourea adducts, $\left[\mathrm{SBr}\left(\mathrm{IPrMe}^{\mathrm{M}}\right)\right] \mathrm{Br}_{3}$ and $[\mathrm{SBr}(\mathrm{ICy})] \mathrm{Br}$, as observed by single-crystal X-ray diffraction analysis. Notably, [S(IPrMe)] and [S(ICy)] have significantly lower oxidation potentials ( $E_{p a}=0.53 \mathrm{~V}$ and $0.52 \mathrm{~V}$, respectively) than all of the other thioureas. This could mean that the decrease in the electronegativity difference between the chalcogen and the halogen, which typically leads to CT adducts, can be offset by a significant increase in oxidation potential difference between the chalcogenourea and the dihalogen, to afford hypervalent adducts. Unlike the reaction of the corresponding selenium analogue, the reaction of $\left[\mathrm{S}(\mathrm{IPr})^{\mathrm{Me}}\right]$ with bromine afforded an Lshaped structure with a tribromide counterion, $\left[\mathrm{SBr}\left(\mathrm{IPr}^{\mathrm{Me}}\right)\right] \mathrm{Br}_{3}$, which is more closely related to [ $\mathrm{SeBr}(\mathrm{SIPr})] \mathrm{Br}_{3}$. Single-crystal $\mathrm{X}$ ray diffraction analysis of $[\mathrm{SBr}(\mathrm{ICy})] \mathrm{Br}$ revealed a pseudo $\mathrm{T}$ shaped structure with a $\mathrm{Br}_{2} \cdots \mathrm{S}_{1}-\mathrm{Br}_{1}$ angle of $177.25(7)^{\circ}$. Interestingly, the $\mathrm{S}_{1} \cdots \mathrm{Br}_{2}$ contact $(2.715(2) \AA)$ is significantly longer than the $S_{1}-B r_{1}$ bond $(2.349(2) \AA)$, which seems to put the $\mathrm{Br}_{2}$ atom at the border between inner- and outer-sphere coordination. Ultimately, this valuable information could allow us to predict the structure of future reaction outcomes between the two reagents based on their electronegativity and oxidation potential differences. 
Table 3. Selected bond lengths $(\AA \AA)$ and angles $\left({ }^{\circ}\right)$ for the dichloroselenoureas

\begin{tabular}{|c|c|c|c|c|c|c|}
\hline Structures & $\mathrm{C}_{1}-\mathrm{Se}_{1}$ & $\mathrm{Se}_{1}-\mathrm{Cl}_{1}$ & $\mathrm{Se}_{1}-\mathrm{Cl}_{2}$ & $\mathrm{C}_{1}-\mathrm{Se}_{1}-\mathrm{Cl}_{1}$ & $\mathrm{C}_{1}-\mathrm{Se}_{1}-\mathrm{Cl}_{2}$ & $\mathrm{Cl}_{1}-\mathrm{Se}_{1}-\mathrm{Cl}_{2}$ \\
\hline$\left[\mathrm{SeCl}_{2}(\mathrm{IPr})\right]$ & $1.895(3)$ & $2.4059(9)$ & $2.4059(9)$ & $90.07(8)$ & $90.07(8)$ & $179.86(3)$ \\
\hline$\left[\mathrm{SeCl}_{2}(\mathrm{SIPr})\right]$ & $1.924(3)$ & $2.4003(10)$ & $2.3896(10)$ & $87.73(8)$ & $88.89(8)$ & $176.60(3)$ \\
\hline$\left[\mathrm{SeCl}_{2}\right.$ (SIMes)] & $1.909(4)$ & $2.4311(10)$ & $2.3725(11)$ & $91.65(10)$ & $89.45(10)$ & $178.87(4)$ \\
\hline$\left[\mathrm{SeCl}_{2}\left(\operatorname{IPr}^{*}\right)\right]$ & $1.900(3)$ & $2.3267(13)$ & $2.5024(15)$ & $91.80(11)$ & $86.75(11)$ & $178.38(5)$ \\
\hline
\end{tabular}

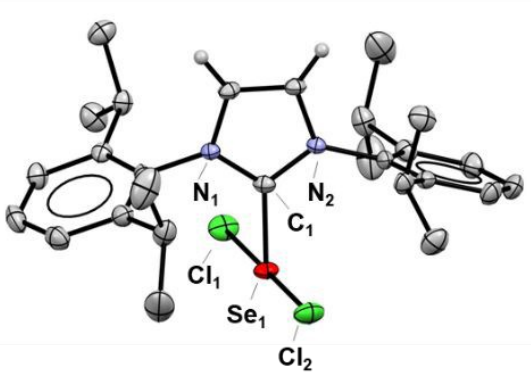

$\left[\mathrm{SeCl}_{2}(\mathrm{IPr})\right]$

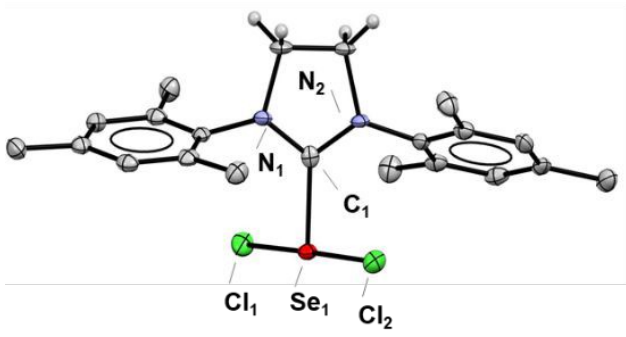

[SeCl ${ }_{2}$ (SIMes)]

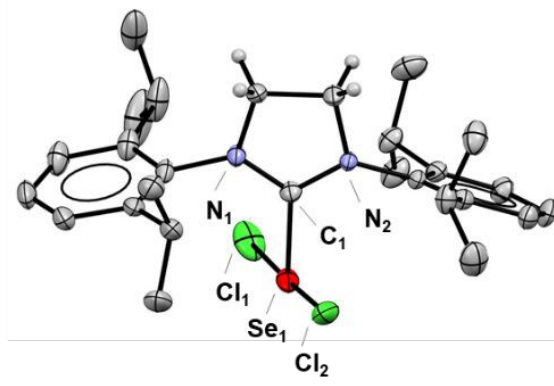

$\left[\mathrm{SeCl}_{2}(\mathrm{SIPr})\right]$

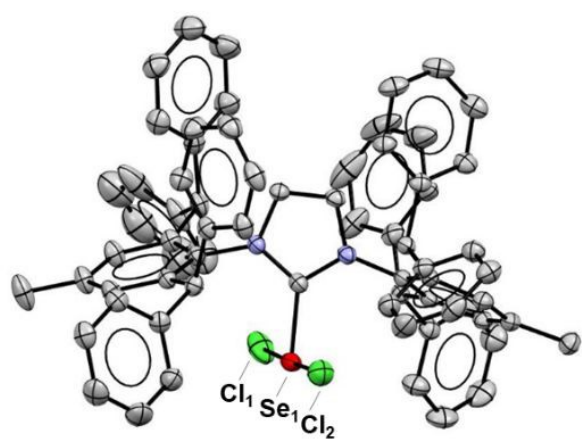

$\left[\mathrm{SeCl}_{2}(\operatorname{IPr} *)\right]$

Figure 7. Molecular structures of $\left[\mathrm{SeCl}_{2}(\mathrm{IPr})\right],\left[\mathrm{SeCl}_{2}(\mathrm{SIPr})\right],\left[\mathrm{SeCl}_{2}\left(\mathrm{SIMes}_{)}\right]\right.$and $\left[\mathrm{SeCl}_{2}\left(\mathrm{IPr}{ }^{*}\right)\right]$, as determined by single-crystal X-ray diffraction analysis. Most hydrogen atoms and solvent molecules are omitted for clarity. Thermal displacement ellipsoids are shown at the $50 \%$ probability level.

\section{Reactions of Chalcogenoureas with Thionyl Chloride}

All the NHC-based seleno- and thioureas were treated with 1.2 equiv. of $\mathrm{SO}_{2} \mathrm{Cl}_{2}$ in dichloromethane (Scheme 4). Besides being a practical and convenient source of $\mathrm{Cl}_{2}, \mathrm{SO}_{2} \mathrm{Cl}_{2}$ is a much stronger oxidant than $\mathrm{Br}_{2}\left(\mathrm{Cl}_{2} / \mathrm{Cl}^{-} ; \mathrm{E}^{\circ}=+1.36 \mathrm{~V}\right)$. Single crystals of the products were grown by vapor diffusion of pentane into a saturated solution of these products in dichloromethane, in an attempt to discern their various structural geometries.

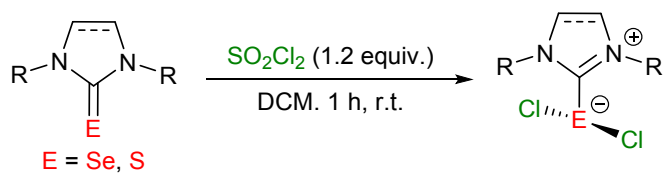

Scheme 4. Reaction of $[\mathrm{E}(\mathrm{NHC})]$ with $\mathrm{SO}_{2} \mathrm{Cl}_{2}$.

\section{[Se(NHC)] reactions with $\mathrm{SO}_{2} \mathrm{Cl}_{2}$}

Even though most selenoureas reacted successfully with $\mathrm{SO}_{2} \mathrm{Cl}_{2}$ to afford new compounds, as confirmed by NMR analysis, we were only able to obtain suitable crystals for four of them.
Single-crystal X-ray diffraction analysis of these four products, derived from the reactions of [Se(IPr)], [Se(SIPr)], [Se(SIMes)] and $\left[\mathrm{Se}\left(\mathrm{IPr}^{*}\right)\right]$ with $\mathrm{SO}_{2} \mathrm{Cl}_{2}$, showed exclusively homolytic breakage of the chlorine-chlorine bond with oxidation of the selenone moiety (Figure 7). All 4 molecular structures exhibited a T-shaped geometry, bearing an almost linear $\mathrm{Cl}-\mathrm{Se}-\mathrm{Cl}$ angle. Previously, Ragogna and co-workers accessed NHC-based dichloroselenoureas by reaction of the free carbene with $\mathrm{SeCl}_{4}$ in a 4:3 ratio. ${ }^{22}$ NMR spectroscopy and single-crystal X-ray analysis revealed a mixture of two carbene-containing compounds in an approximately 1:1 ratio; these were the expected $\left[\mathrm{SeCl}_{2}(\mathrm{NHC})\right]$ compound and the by-product of $\mathrm{Cl}$ insertion to the carbene, $[\mathrm{NHC}-\mathrm{Cl}]_{2}\left[\mathrm{SeCl}_{6}\right]$. However, in this study, the latter by-product was never observed.

Molecular X-ray structures for $\left[\mathrm{SeCl}_{2}(\mathrm{IPr})\right],\left[\mathrm{SeCl}_{2}(\mathrm{SIPr})\right]$, $\left[\mathrm{SeCl}_{2}(\mathrm{SIMes})\right]$ and $\left[\mathrm{SeCl}_{2}\left(\mathrm{IPr}^{*}\right)\right]$ are presented in Figure 7. All show the $\mathrm{Cl}-\mathrm{Se}-\mathrm{C}_{1}$ angles to be around $90^{\circ}$; all of the $\mathrm{Cl}-\mathrm{Se}-\mathrm{C}_{1}-\mathrm{N}$ torsion angles are about $15^{\circ}$ to $28^{\circ}$ from the perpendicular plane, meaning that the $\mathrm{SeCl}_{2}$ moiety is not perfectly perpendicular to the ligand plane (Table 3 ). All structures show 
similar Se-Cl bond lengths with an average distance of $2.4 \AA$. These values are comparable to the previously reported Se-Cl

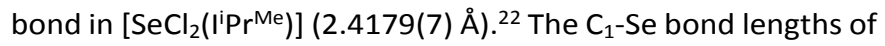
these molecules (with respective values of 1.897(3), 1.924(3), 1.909 (4) and 1.900(3) Å) are comparable to those observed with the dibromo analogues and follow a similar trend with a more pronounced single bond character observed for the selenoureas derived from saturated NHCs. For $\left[\mathrm{SeCl}_{2}(\mathrm{SIPr})\right]$ and [SeCl${ }_{2}$ (SIMes)], small differences between the $\mathrm{Se}-\mathrm{Cl}_{1}$ and $\mathrm{Se}-\mathrm{Cl}_{2}$ bond lengths in each compound are observed. This again may be explained by weak intra- and inter-molecular interactions between the $\mathrm{Cl}$ and $\mathrm{H}$ atoms, as shown for $\left[\mathrm{SeCl}_{2}(\mathrm{SIPr})\right]$ in Figure 8.

\section{[S(NHC)] reactions with $\mathrm{SO}_{2} \mathrm{Cl}_{2}$}

Attempts to probe the reactions between the NHC-based thioureas and thionyl chloride did not lead to the clean formation of new products, but instead produced multiple unidentified by-products as well as significant levels of decomposition; however, suitable crystals for X-ray diffraction analysis were obtained from the reaction of [S(SIMes)] with thionyl chloride, which identified one of the by-products as [SIMes-Cl] $\mathrm{HSO}_{4}$ (Figure 9). ${ }^{1} \mathrm{H}$ NMR analysis of the reaction mixture indicated that this compound is only one of the minor by-products, but unfortunately, we were not able to identify any other components of the reaction mixture. [SIMes-CI] $\mathrm{HSO}_{4}$ is clearly formed via chloride insertion and cleavage of the $\mathrm{C}_{1}-\mathrm{S}$ bond, though the exact mechanism for forming the $\mathrm{HSO}_{4}$ counterion is still unknown. In the structure of [SIMes-Cl] $\mathrm{HSO}_{4}$, short $\mathrm{Cl} \cdots \mathrm{O}$ bonds are observed between the $\mathrm{NHC}$ ligand and the $\mathrm{HSO}_{4}{ }^{-}$counter ion (2.806(3) $\AA$ and 2.874(3) $\AA$, for both formula units in the asymmetric unit, respectively).

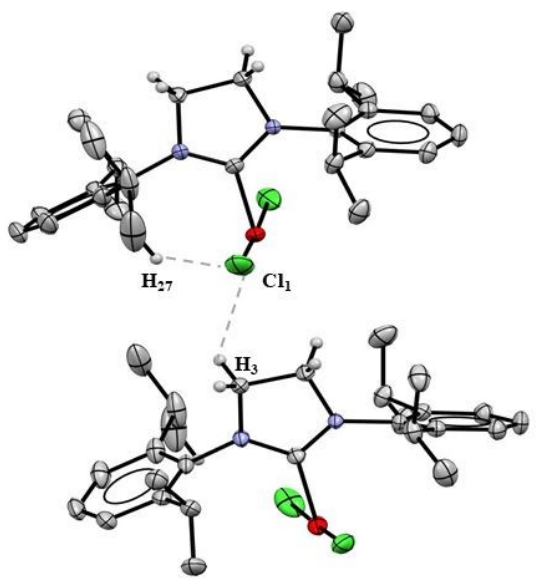

Figure 8. Partial view of the crystal packing of $\left[\mathrm{SeCl}_{2}(\mathrm{SIPr})\right]$ showing the intramolecular bond interaction $\mathrm{Cl}_{1}-\mathrm{-}-\mathrm{H}_{27}(2.62 \AA)$ and intermolecular bond interaction $\mathrm{Cl}_{1}-\mathrm{-}-\mathrm{H}_{3}(2.62$ $\AA$ ).

It should be noted that this phenomenon is not new and has been observed in the reactions of $\mathrm{N}$-methylthiazolidine-2selone with excess bromine. ${ }^{23}$ Whether the $\mathrm{HSO}_{4}^{-}$, in this case, is formed directly from the cleaved $\mathrm{S}$ atom or from the liberated $\mathrm{SO}_{2}$ is still unclear at this point. In addition, we can't exclude the fact that adventitious water (from the $\mathrm{SO}_{2} \mathrm{Cl}_{2}$ reagent) ${ }_{A}$ might be involved in its formation. DOI: 10.1039/D2DT00010E

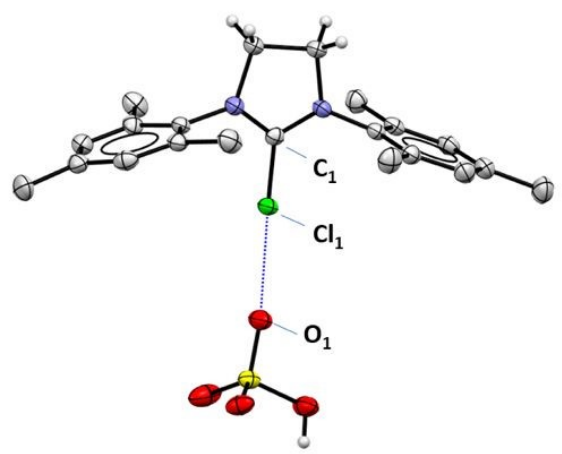

Figure 9. Molecular structure of [SIMes-Cl] $\mathrm{HSO}_{4}$ as determined by single-crystal X-ray diffraction analysis, showing the $\mathrm{Cl} \cdots \mathrm{O}$ bond $(2.806(3) \AA)$; only one formula unit in the asymmetric unit is shown. Most hydrogen atoms and solvent molecules are omitted for clarity. Thermal displacement ellipsoids are shown at the $50 \%$ probability level.

\section{Reactions of Chalcogenoureas with lodine}

As summarized in Scheme 5, all the seleno- and thiourea NHCs were treated with 1.5 equiv. of iodine in acetone, resulting in complete conversion to new compounds as indicated by NMR spectroscopy. Single crystals were grown by vapor diffusion of pentane into a saturated solution of these products in dichloromethane.

Scheme 5. Possible products from the reaction of $[\mathrm{E}(\mathrm{NHC})]$ with $\mathrm{I}_{2}$.

\section{[Se(NHC)] reactions with $\mathrm{I}_{2}$}

Single-crystal X-ray diffraction analysis of the seleniumcontaining products formed after iodination showed several types of coordination arrangement (Figures 10 and 11). The products derived from the reactions of iodine with [Se(IPr)], [Se(IMes)], [Se(SIMes)] and [Se(IPr $\left.\left.{ }^{C l}\right)\right]$ displayed CT-type structures (Figure 10), as expected based on the oxidation potentials of iodine vs [Se(NHC)] (vide supra), wherein the selenium atom is linearly coordinated to the iodine $\left(\mathrm{I}_{2}\right)$ molecule with Se- $I_{1}-I_{2}$ angles from $168.69(3)^{\circ}$ to $178.81(3)^{\circ}$. The lengthening of the $\mathrm{C}_{1}$-Se bond (1.85-1.88 $\AA$ ) is also observed for all four products, compared to the initial $\mathrm{C}_{1}$-Se bond ( $c a .1 .83 \AA$ ) of the starting selenoureas [Se(NHC)] (Table 4). The $I_{1}-I_{2}$ bonds in these complexes are significantly longer than the I-I bond in molecular iodine ( $c a .2 .677 \AA$ in the gas phase and $2.717 \AA$ at $110 \mathrm{~K}$ in crystal form)..$^{24}$ 
Table 4. Selected bond lengths $(\AA)$ and angles $\left({ }^{\circ}\right)$ for the diiodothio- and selenoureas.

\begin{tabular}{|c|c|c|c|c|c|}
\hline Structure & $\mathrm{C}_{1}-\mathrm{E}_{1}$ & $E_{1}-I_{1}$ & $I_{1}-I_{2}$ & $C_{1}-E_{1}-I_{1}$ & $E_{1} \cdot I_{1}-I_{2}$ \\
\hline$\left[\left(I_{2}\right) \cdot \operatorname{Se}(\operatorname{IPr})\right]$ & $1.872(3)$ & $2.7039(5)$ & $2.9870(4)$ & $97.43(11)$ & $178.34(13)$ \\
\hline$\left[\left(\mathrm{I}_{2}\right) \cdot \mathrm{Se}(\mathrm{IMes})\right]$ & $1.852(9)$ & $2.7716(10)$ & $2.9177(8)$ & $95.40(2)$ & $178.81(3)$ \\
\hline$\left[\left(\mathrm{I}_{2}\right) \cdot \operatorname{Se}(\mathrm{SIMes})\right]^{a}$ & $1.860(7)-1.880(6)$ & $2.7478(9)-2.7642(10)$ & $2.9106(7)-2.9411(6)$ & $112.96(18)-115.6(2)$ & $168.69(3)-172.14(3)$ \\
\hline$\left[\left(\mathrm{I}_{2}\right) \cdot \operatorname{Se}\left(\mid \operatorname{Pr}^{\mathrm{C}}\right)\right]$ & $1.865(3)$ & $2.8431(3)$ & $2.8470(4)$ & $115.30(8)$ & $174.95(9)$ \\
\hline$\left[\left(I_{2}\right) \cdot S(\operatorname{IPr} *)\right]$ & $1.692(3)$ & $2.8381(8)$ & $2.7711(3)$ & $118.06(9)$ & $175.31(16)$ \\
\hline$\left[\left(\mathrm{I}_{2}\right) \cdot \mathrm{S}(\mathrm{IMes})\right]$ & $1.707(3)$ & $2.7251(7)$ & $2.8648(3)$ & $98.13(10)$ & $177.61(2)$ \\
\hline$\left[\left(I_{2}\right) \cdot S(I C y)\right]$ & $1.715(8)$ & $2.628(2)$ & $2.9787(8)$ & $97.8(3)$ & $179.26(6)$ \\
\hline
\end{tabular}

${ }^{a}$ Asymmetric unit contains 5 molecules, only the range of values is shown in the table.
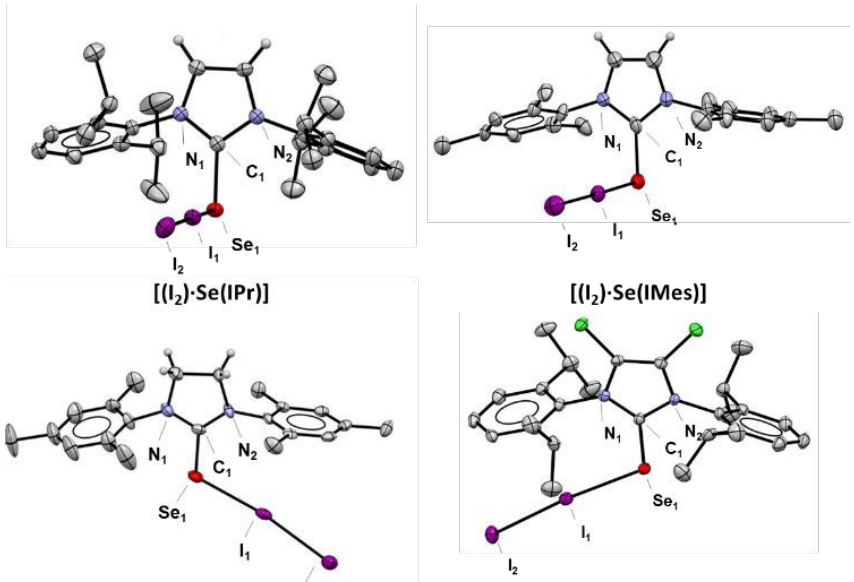

$\left[\left(I_{2}\right) \cdot \operatorname{Se}(S I M e s)\right]^{I_{2}}$

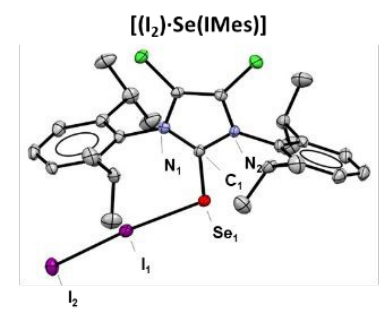

$\left[\left(\mathrm{I}_{2}\right) \cdot \operatorname{Se}\left(\mid \mathrm{Pr}^{\mathrm{Cl}}\right)\right]$

Figure 10. Molecular structures of $\left[\left(I_{2}\right) \cdot \operatorname{Se}(\operatorname{IPr})\right],\left[\left(I_{2}\right) \cdot \operatorname{Se}(I \mathrm{Mes})\right],\left[\left(\mathrm{I}_{2}\right) \cdot \mathrm{Se}(\mathrm{SIMes})\right]$ and $\left[\left(\mathrm{I}_{2}\right) \cdot \mathrm{Se}\left(\mathrm{IPr}^{\mathrm{Cl}}\right)\right]$ as determined by single-crystal X-ray diffraction analysis. Most hydrogen atoms and solvent molecules are omitted for clarity. Thermal displacement ellipsoids are shown at the $50 \%$ probability level.

Based on their relatively low oxidation potentials $(0.41 \mathrm{~V})$, which are the lowest in the series, there was a possibility that [Se(IPrMe)] and [Se(ICy)] might afford hypervalent selenourea adducts after iodination; fortunately, both compounds gave suitable crystals for X-ray diffraction analysis (Figure 11). The product obtained from the reaction of [Se(ICy)] with iodine was confirmed to be a T-shaped hypervalent diiodo-selenourea adduct, with a $I_{1}-\mathrm{Se}-I_{2}$ bond angle of $174.57(3)^{\circ}$. This structure is similar to the bromo analogue and shows slight lengthening of the $C_{1}$-Se bond (from 1.852(2) to 1.891(7) $\AA$ ) and shortening of the $\mathrm{N}-\mathrm{C}_{1}$ bonds (from 1.36(3) to $1.342(7) \AA$, on average). Analogously to the bromo analogue, inter- and intra-molecular $\mathrm{I}-\mathrm{-}-\mathrm{H}$ bond interactions create a slight dissymmetry in the $\mathrm{Se}_{1}-\mathrm{I}$ bond lengths (with values of $2.7643(7)$ and $2.8670(7) \AA$ ). A similar outcome has been previously observed from the products of the reactions of benzimidazole-based selenoureas with iodine. ${ }^{25}$

As initially predicted, a hypervalent L-shaped structure, $\left[\mathrm{Sel}\left(\mathrm{IPrMe}^{\mathrm{Me}}\right)\right]_{3}$, was obtained from the reaction of [Se(IPrMe)] and iodine. As shown in Table 1, [ $\mathrm{Se}(\mathrm{ICY})]$ and $\left[\mathrm{Se}\left(\mathrm{IPr}^{\mathrm{Me}}\right)\right]$ possess the same low oxidation potential $\left(\mathrm{E}_{\mathrm{pa}}=+0.41 \mathrm{~V}\right)$ and were thus expected to afford hypervalent selenourea adducts.

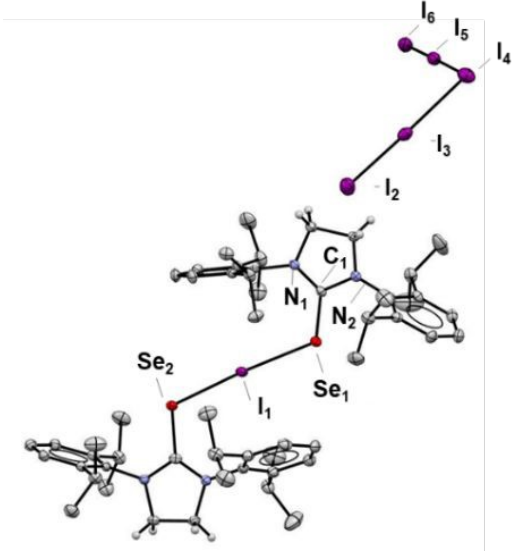

$\left[\{\operatorname{Se}(\operatorname{SIPr})\}_{2}(\mu-1)\right] I_{5}$

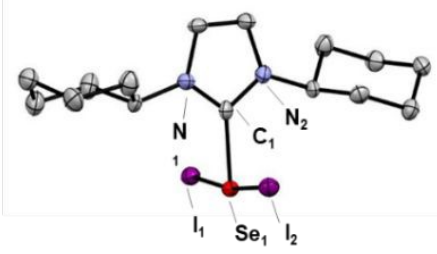

[Sel $($ ICy)]

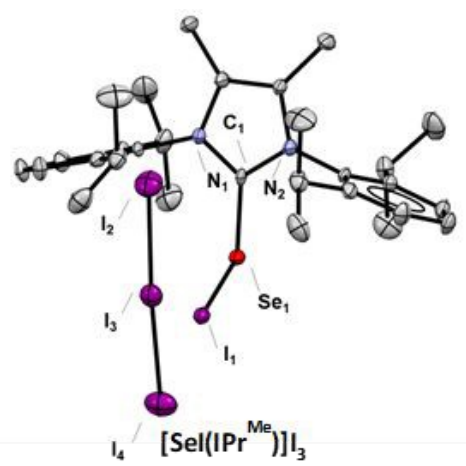

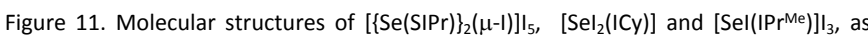
determined by single-crystal $\mathrm{X}$-ray diffraction analysis. Most hydrogen atoms and solvent molecules are omitted for clarity. Thermal displacement ellipsoids are shown at the 50\% probability level.

The crystals from the reaction of [Se(SIPr)] and iodine were analyzed by $\mathrm{X}$-ray diffraction and gave a rather unexpected result (Figure 11). Based on the oxidation potential of [Se(SIPr)] 
$\left(E_{p a}=+0.69 \mathrm{~V}\right)$, and if the current trend is to be followed, a CTtype structure was expected. However, a new ionic structure was observed, specifically $\left[\{\mathrm{Se}(\mathrm{SIPr})\}_{2}(\mu-\mathrm{I})\right] \mathrm{I}_{5}$, a iodine $(\mathrm{I})$ complex with two selenoureas coordinated. This structural geometry has been observed in previous reports, from the reactions of benzothiazole-based thiones and selones with iodine. ${ }^{14,23}$ The formation of the $\mathrm{I}_{5}{ }^{-}$anion has been observed even when iodine is added under strictly $1: 1$ stoichiometric conditions; ${ }^{14,23}$ as previously noted, this appears to only be a solid-state phenomenon.

[Se(SIPr)] has been shown to consistently give peculiar and puzzling ionic structures, such as the L-shaped bromo analogue in this report (Figure 4) and other rearranged structures of the form $\left[\mathrm{M}\{\mathrm{Se}(\mathrm{NHC})\}_{2}\right]^{+}$which has been observed when coordinating to group 11 metals (i.e., $\mathrm{M}=\mathrm{Cu}, \mathrm{Ag}, \mathrm{Au}$ ). ${ }^{17 \mathrm{a}}$ Except for the $\mathrm{I}_{5}{ }^{-}$anion, $\left[\mathrm{Mt}\{\mathrm{Se}(\mathrm{SIPr})\}_{2}\right]^{+}$is almost identical to the current one, $\left[\{\mathrm{Se}(\mathrm{SIPr})\}_{2}(\mu-\mathrm{I})\right]^{+}$. So far, our best explanation for this phenomenon is the exceptionally high $\pi$-accepting ability of the SIPr moiety when compared to all other NHCs in the series. The $(E-I-E)^{+}$moiety does not appear to be symmetrical as the two Se- $I_{1}$ bond lengths are not equal, with values of 2.8112(5) for $\mathrm{Se}_{1}-\mathrm{I}_{1}$ and 2.7238(5) for $\mathrm{Se}_{2}-\mathrm{I}_{1}$. Furthermore, the C-Se-I angle shifts significantly from the $90^{\circ}$ angle observed so far for the other ionic structures, and is different for each [Se(SIPr)] moiety $\left(115.62(13)^{\circ}\right.$ for $\mathrm{C}_{1}-\mathrm{Se}_{1}-\mathrm{I}_{1}$ and $111.94(13)$ for $\left.\mathrm{I}_{1}-\mathrm{Se}_{2}-\mathrm{C}_{2}\right)$; these angles are closer in magnitude to those observed in CT adducts. The $\mathrm{Se}_{1}-\mathrm{I}_{1}-\mathrm{Se}_{2}$ moiety shows an almost linear arrangement with an angle of $176.017(17)^{\circ}$. $I_{2}-I_{3}-I_{4}$ and $I_{4}-I_{5}-I_{6}$ are also close to linear with angles of $178.540(15)^{\circ}$ and $178.583(15)^{\circ}$, respectively, and are perpendicular to each other with an angle of $93.97(12)^{\circ}$.

\section{$S(N H C)]$ reactions with $I_{2}$}

While all thioureas underwent successful reaction with iodine to afford full conversion to new compounds, as confirmed by NMR analysis, we were only able to obtain suitable crystals for three of these products. Single-crystal X-ray diffraction analysis of products derived from the reactions of [S(IPr*)] and [S(IMes)] with $I_{2}$, showed exclusive formation of CT-type adducts (Figure 12). These results were expected considering the high oxidation potential of the corresponding thioureas. Crystals for the product derived from the reaction of $[\mathrm{S}(\mathrm{ICy})]$ with iodine were also analyzed, showing again a CT-type structure (Figure 12).
Nonetheless, this information is crucial since $[S(J C Y)) d_{r}$ thas, the lowest $E_{p a}$ in the thiourea series. This stropligy saggests that, if the trend is followed, all the thioureas reported herein are expected to exclusively give CT adducts. Unfortunately, suitable single crystals for the $[S(S I P r)]$ iodination product could not be obtained.
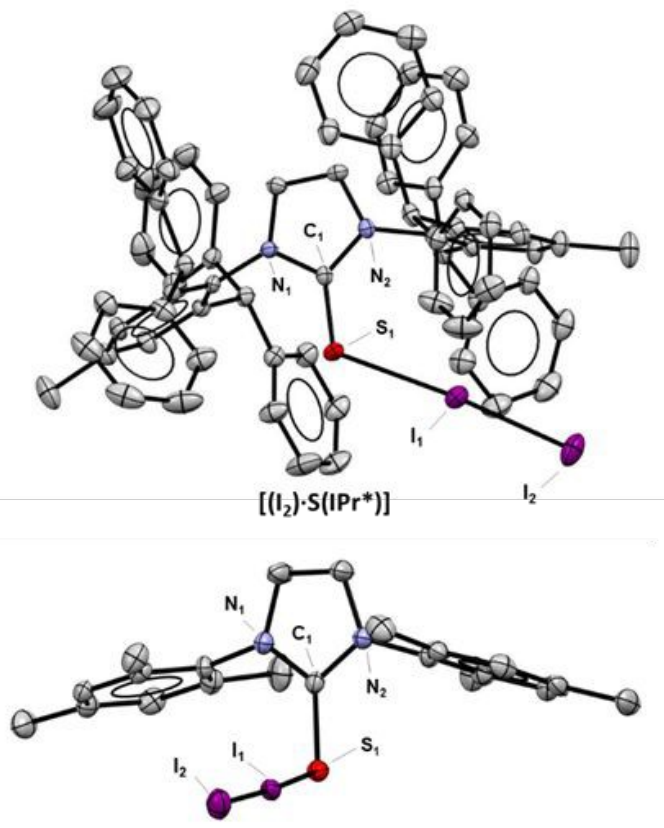

$\left[\left(I_{2}\right) \cdot S(I M e s)\right]$

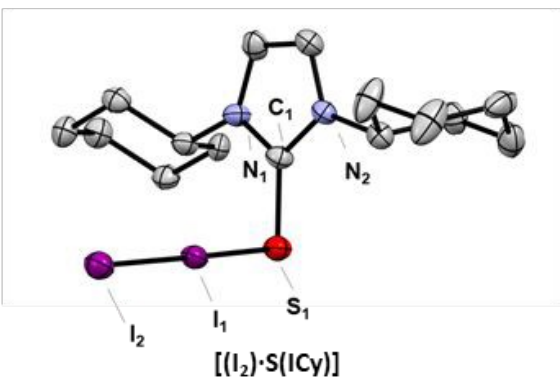

Figure 12. Molecular structures of $\left[\left(\mathrm{I}_{2}\right) \cdot \mathrm{S}\left(\mathrm{IPr} \mathrm{Pr}^{*}\right)\right],\left[\left(\mathrm{I}_{2}\right) \cdot \mathrm{S}(\mathrm{IMes})\right]$ and $\left[\left(\mathrm{I}_{2}\right) \cdot \mathrm{S}(\mathrm{ICy})\right]$, as determined by single-crystal $\mathrm{X}$-ray diffraction analysis. Most hydrogen atoms and solvent molecules are omitted for clarity. Thermal displacement ellipsoids are shown at the 50\% probability level. 
Table 5. Summary of the structures and coordination types obtained in this study.

\begin{tabular}{|c|c|c|c|c|c|c|c|c|}
\hline \multirow[b]{2}{*}[\mathrm{E}(\mathrm{NHC})]{} & \multirow[b]{2}{*}{$\begin{array}{c}{ }^{77} \mathrm{Se} N \mathrm{NMR} \\
\text { (ppm) }\end{array}$} & \multirow[b]{2}{*}{$\begin{array}{c}\text { Epa vs Fc } \\
\text { (V) }\end{array}$} & \multicolumn{2}{|c|}{ Reaction with $\mathrm{Br}_{2}$} & \multicolumn{2}{|c|}{ Reaction with $\mathrm{I}_{2}$} & \multicolumn{2}{|c|}{ Reaction with $\mathrm{Cl}_{2}$} \\
\hline & & & Structure & $\begin{array}{c}\text { Coordination } \\
\text { type }\end{array}$ & Structure & $\begin{array}{c}\text { Coordination } \\
\text { type }\end{array}$ & Structure & $\begin{array}{c}\text { Coordination } \\
\text { type }\end{array}$ \\
\hline [Se(IPr)] & 90 & 0.52 & {$\left[\mathrm{SeBr}_{2}(\mathrm{IPr})\right]$} & Ionic T-shape & {$\left[\left(\mathrm{I}_{2}\right) \cdot \mathrm{Se}(\mathrm{IPr})\right]$} & $\mathrm{CT}$ adduct & {$\left[\mathrm{SeCl}_{2}(\mathrm{IPr})\right]$} & Ionic T-shape \\
\hline [Se(SIPr)] & 190 & 0.69 & {$[\mathrm{SeBr}(\mathrm{SIPr})] \mathrm{Br}_{3}$} & Ionic L-shape & {$\left[\{\mathrm{Se}(\mathrm{SIPr})\}_{2}(\mu-1)\right] \mathrm{I}_{5}$} & Ionic E-X-E & {$\left[\mathrm{SeCl}_{2}(\mathrm{SIPr})\right]$} & Ionic T-shape \\
\hline [Se(IMes)] & 27 & 0.57 & {$\left[\mathrm{SeBr}_{2}(\mathrm{IMes})\right]$} & Ionic T-shape & {$\left[\left(\mathrm{I}_{2}\right) \cdot \mathrm{Se}(\mathrm{IMes})\right]$} & $\mathrm{CT}$ adduct & NC & - \\
\hline [Se(SIMes)] & 110 & 0.67 & {$\left[\mathrm{SeBr}_{2}(\mathrm{SIMes})\right]$} & Ionic T-shape & {$\left[\left(I_{2}\right) \cdot \operatorname{Se}(\mathrm{SIMes})\right]$} & $\mathrm{CT}$ adduct & {$\left[\mathrm{SeCl}_{2}(\mathrm{SIMes})\right]$} & Ionic T-shape \\
\hline$\left[\mathrm{Se}\left(\mathrm{IPr}^{\mathrm{Me}}\right)\right]$ & 105 & 0.41 & {$\left[\mathrm{SeBr}_{2}\left(\mathrm{IPr}^{\mathrm{Me}}\right)\right]$} & Ionic T-shape & {$\left[\mathrm{Sel}\left(\mathrm{IPrMe}^{\mathrm{Me}}\right)\right] \mathrm{I}_{3}$} & Ionic L-shape & $\mathrm{NC}$ & - \\
\hline$\left[\mathrm{Se}\left(\operatorname{IPr}^{\mathrm{Cl}}\right)\right]$ & 174 & 0.76 & {$\left[\mathrm{SeBr}\left(\operatorname{IPr}^{\mathrm{Cl}}\right)\right] \mathrm{Br}_{3}$} & Ionic L-shape & {$\left[\left(I_{2}\right) \cdot \operatorname{Se}(\operatorname{IPr})\right]$} & $\mathrm{CT}$ adduct & NC & - \\
\hline$[\mathrm{Se}(\operatorname{IPr} *)]$ & 106 & 0.74 & NC & - & NC & - & {$\left[\mathrm{SeCl}_{2}\left(\mathrm{IPr}^{*}\right)\right]$} & Ionic T-shape \\
\hline [Se(ICy)] & -22 & 0.41 & {$\left[\mathrm{SeBr}_{2}(\mathrm{ICy})\right]$} & Ionic T-shape & {$\left[\mathrm{Sel}_{2}(\mathrm{ICy})\right]$} & Ionic T-shape & NC & - \\
\hline$[\mathrm{S}(\mathrm{IPr})]$ & - & 0.77 & NC & - & NC & - & DR & - \\
\hline [S(SIPr)] & - & 1.09 & $\mathrm{NC}$ & - & NC & - & DR & - \\
\hline [S(IMes)] & - & 0.73 & {$\left[\left(\mathrm{Br}_{2}\right) \cdot \mathrm{S}(\mathrm{IMes})\right]$} & $\mathrm{CT}$ adduct & {$\left[\left(\mathrm{I}_{2}\right) \cdot \mathrm{S}(\mathrm{IMes})\right]$} & $\mathrm{CT}$ adduct & $\mathrm{DR}$ & - \\
\hline [S(SIMes)] & - & 1.08 & {$\left[\left(\mathrm{Br}_{2}\right) \cdot S(\mathrm{SIMes})\right]$} & $\mathrm{CT}$ adduct & NC & - & DR & - \\
\hline$\left[\mathrm{S}\left(\mathrm{IPr}^{\mathrm{Me}}\right)\right]$ & - & 0.53 & {$\left[\mathrm{SBr}\left(\operatorname{IPr} \mathrm{Pe}^{\mathrm{Me}}\right)\right] \mathrm{Br}_{3}$} & Ionic L-shape & NC & - & DR & - \\
\hline$\left[S\left(\mid P r r^{C}\right)\right]$ & - & 0.96 & $\mathrm{NC}$ & - & NC & - & $\mathrm{DR}$ & - \\
\hline$\left[\mathrm{S}\left(\mathrm{IPr} \mathrm{Pr}^{*}\right)\right]$ & - & 0.87 & NC & - & {$\left[\left(\mathrm{I}_{2}\right) \cdot \mathrm{S}\left(\mathrm{IPr}^{*}\right)\right]$} & $\mathrm{CT}$ adduct & DR & - \\
\hline$[S(I C y)]$ & - & 0.52 & {$[\mathrm{SBr}(\mathrm{ICy})] \mathrm{Br}$} & Ionic L-shape & {$\left[\left(I_{2}\right) \cdot S(I C y)\right]$} & $\mathrm{CT}$ adduct & $\mathrm{DR}$ & - \\
\hline
\end{tabular}

NC: no suitable crystals was obtained. DR: decomposition during the reaction.

\section{Conclusions}

In summary, cyclic voltammetry measurements were performed on seleno- and thiourea-based NHCs. As expected, selenoureas were shown to be easier to oxidize than their thioanalogues. In some cases, the different electronic properties of the NHC moiety were influencing the oxidation potential of the corresponding chalcogenourea. For example, chalcogenoureas derived from NHCs with unsaturated backbones, i.e., SIPr and SIMes, exhibited higher oxidation potentials than their unsaturated analogues. The presence of electron-donating alkyl substituents on the backbone (e.g., I $\mathrm{Pr}^{\mathrm{Me}}$ ) or on the nitrogen atom (e.g., ICy) of the imidazole ring seemed to have a stabilizing effect, which in turn lowered the oxidation potential of the corresponding chalcogenourea. Meanwhile, electronwithdrawing groups on the backbone (e.g., $\mid \mathrm{Pr}^{\mathrm{Cl}}$ ) showed the opposite effect. The oxidative halogenation of the herein reported chalcogenoureas was also successfully investigated using $\mathrm{Br}_{2}, \mathrm{I}_{2}$ and $\mathrm{SO}_{2} \mathrm{Cl}_{2}$ as halogenating reagents. Single-crystal $\mathrm{X}$-ray diffraction analysis was used to identify the solid-state coordination pattern of the obtained products (Table 5). The results obtained in this report showed that, when taking into account the oxidation potential of the corresponding starting chalcogenourea and the difference in electronegativity between the chalcogen and the halogen, we are now better able to predict the coordination type in the final products. This is still far from being ideal, as we are still not able to obtain any quantifiable trends/correlations. However, we are confident that this work constitutes a step forward in the right direction for this exciting area of research.

\section{Conflicts of interest}

There are no conflicts to declare".

\section{Acknowledgements}

MS and KVH thank the Research Foundation - Flanders (FWO) (project AUGE/11/029) and the Special Research Fund (BOF) UGent (project 01N03217) for funding.

\section{Notes and references}

¥ Crystallographic data underpinning this study can be downloaded from the Cambridge Structural Database (CSD) via the following link: https://www.ccdc.cam.ac.uk/structures/ (CCDC 2121842-2121867). See supporting information for more details.

1 (a) M. N. Hopkinson, C. Richter, M. Schedler and F. Glorius, Nature, 2014, 510, 485-496; (b) A. J. Arduengo III, R. L. Harlow and M. Kline, J. Am. Chem. Soc., 1991, 113, 361; (c) A. H. Cowley, Pure Appl. Chem., 1998, 70, 765-768; d) W. A. Herrmann, O. Runte and G. R. J. Artus, J. Organomet. Chem., 
1995, 501, C1-C4; (e) S. P. Green, C. Jones, K.-A. Lippert, D. P. Mills and A. Stasch, Inorg. Chem., 2006, 45, 7242-7251; (f) W. W. Schoeller, Inorg. Chem., 2011, 50, 2629-2633.

2 (a) Y. Wang and G. H. Robinson, Organometallics, 2007, 26, 2 11; (b) P. A. Rupar, V. N. Staroverov, P. J. Ragogna and K. M. Baines, J. Am. Chem. Soc., 2007, 129, 15138-15139; (c) P. A Rupar, M. C. Jennings, P. J. Ragogna and K. M. Baines, Organometallics, 2007, 26, 4109-4111; (d) C. D. Martin, M. C. Jennings, M. J. Ferguson and P. J. Ragogna, Angew. Chem. Int Ed., 2009, 48, 2210-2213; (e) S. Yao, Y. Xiong and M. Driess, Chem. Commun., 2009, 6466-6468; (f) A. C. Filippou, O Chernov, B. Blom, K. W. Stumpf and G. Schnakenburg, Chem Eur. J., 2010, 16, 2866-2872; (g) N. Holzmann, A. Stasch, C. Jones and G. Frenking, Chem. Eur. J., 2011, 17, 13517-13525; (h) J. Xu, Y.-H. Ding, D. M. Andrada and G. Frenking, Chem. Eur. J., 2014, 20, 9216-9220; (i) Y. Wang and G. H. Robinson, Inorg. Chem., 2014, 53, 11815-11832; (j) Y. Wang, M. Chen, Y. Xie, P. Wei, H. F. Schaefer III and G. H. Robinson, J. Am. Chem. Soc., 2015, 137, 8396-8399.

3 (a) M. T. Aroz, M. C. Gimeno, M. Kulcsar, A. Laguna and V. Lippolis, Eur. J. Inorg. Chem., 2011, 2884- 2894; (b) A. Doddi, M. Peters and M. Tamm, Chem. Rev., 2019, 119, 6994-7112; (c) J. E. McDonough, A. Mendiratta, J. J. Curley, G. C. Fortman, S. Fantasia, C. C. Cummins, E. V. Rybak-Akimova, S. P. Nolan and C. D. Hoff, Inorg. Chem., 2008, 47, 2133-2141; (d) N. Nakata, F. Kawauchi, S. Takahashi and A. Ishii, New J. Chem., 2019, 43, 10894-10898; (e) S. Yadav, R. Deka and H. B. Singh, Chem. Lett., 2019, 48, 65-79; (f) Y. Rong, A. Al-Harbi, B. Kriegel and G. Parkin, Inorg. Chem., 2013, 52, 7172-7182; (g) V. K. Landry, M. Minoura, K. Pang, D. Buccella, V. Kelly and G Parkin, J. Am. Chem. Soc., 2006, 128, 12490-12497; (h) A Dreab, M. I. Brewer, C. A. Bayse, J. Inorg. Biochem., 2019, 193, 9-14.

4 (a) Y. Yamashita, T. Yabu and M. Yamashita, World J. Biol. Chem., 2010, 1, 144-50; (b) N. Kroepfl, K. B. Jensen, K. A Francesconi and D. Kuehnelt, Anal. Bioanal. Chem., 2015, 407, 7713-7719.

5 M. T. Zimmerman, C. A. Bayse, R. R. Ramoutar and J. L. Brumaghim, J. Inorg. Biochem., 2015, 145, 30-40.

6 G. Roy, P.N. Jayaram and G. Mugesh, Chem. Asian J., 2013, 8, 1910-1921.

7 M. Banerjee, R. Karri, K.S. Rawat, K. Muthuvel, B. Pathak and G. Roy, Angew. Chem., 2015, 54, 9323-9327.

8 (a) A. Mancini, M. C. Aragoni, N. Bricklebank, C. Castellano, F. Demartin, F. Isaia, V. Lippolis, A. Pintus and M. Arca, Chem. Asian J., 2013, 8, 639; (b) D. Manna, G. Roy and G. Mugesh, Acc. Chem. Res., 2013, 46, 2706; (c) F. Isaia, M. C. Aragoni, M. Arca, C. Caltagirone, F. Demartin, A. Garau and V. Lippolis., Dalton Trans., 2013, 42, 492-498.

9 P. D. Boyle and S. M. Godfrey, Coord. Chem. Rev., 2001, 223, 265-299.

10 (a) F. Bigoli, F. Demartin, P. Deplano, F. A. Devillanova, F. Isaia, V. Lippolis, M. L. Mercuri, M. A. Pellinghelli and E. F. Trogu, Inorg. Chem., 1996, 35, 3194-3201; (b) F. Demartin, F. A. Devillanova, F. Isaia, V. Lippolis and G. Verani, Inorganica Chim. Acta, 1997, 255, 203-205; (c) J. Choi, J. H. Ko, G. Jung, H. Y. Yang, K. C. Ko, J. Y. Lee, S. M. Lee, H. J. Kim, J. H. Nam, J. R Ahn and S. U. Son, Chem. Mater., 2009, 21, 2571-2573; (d) G. Roy, K. P. Bhabak and G. Mugesh, Cryst. Growth Des., 2011, 11, 2279-2286.

11 S. Yadav, S. T. Manjare, H. B. Singh and R. J. Butcher, Dalton Trans., 2016, 45, 12015-12027.

12 S. T. Manjare, S. Yadav, H. B. Singh and R. J. Butcher, Eur. J. Inorg., Chem. 2013, 5344-5357.

13 (a) M. C. Aragoni, M. Arca, F. Demartin, F. A. Devillanova, A Garau, F. Isaia, V. Lippolis and G. Verani, Coord. Chem. Rev., 1999, 184, 271; (b) F. Cristiani, F. Devillanova, F. Isaia, V. Lippolis and F. Verani, Polyhedron, 1995, 14, 2937; (c) M. C.
Aragoni, M. Arca, F. Demartin, F. Devillanova, A. Garau, F.

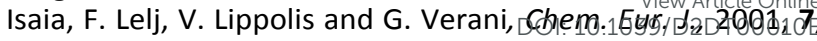
3122; (d) F. Demartin, F. A. Devillanova, F. Isaia, V. Lippolis and G. Verani, Inorg. Chem., 1993, 32, 3694; (e) F. Demartin, F. A Devillanova, A. Garau, F. Isaia, V. Lippolis and G. Verani, Polyhedron, 1999, 18, 3107; (f) D. L. Nosco, M. J. Heeg, M. D. Glick, R. C. Elder and E. Deutsch, J. Am. Chem. Soc., 1980, 102 7784; (g) V. Daga, S. K. Hadjikakou, N. Hadjiliadis, M. Kubicki, J. H. Z. D. Santos and I. S. Butler, Eur. J. Inorg. Chem., 2002, 1718; (h) C. D. Antoniadis, S. K. Hadjikakou, N. Hadjiliadis, M. Kubicki and I. S. Butler, Eur. J. Inorg. Chem., 2004, 4324; (i) C. D. Antoniadis, S. K. Hadjikakou, N. Hadjiliadis, M. Kubicki and I. S. Butler, New. J. Chem., 2005, 29, 714; (j) G. J. Corban, S. K. Hadjikakou, N. Hadjiliadis, M. Kubicki, E. R. T. Tiekink, S. Butler, E. Drougas and A. M. Kosmas, Inorg. Chem., 2005, 44, 8617-8627.

14 M. Arca, M. C. Aragoni, F. Devillanova, A. Garau, F. Isaia, V. Lippolis, A. Mancini and G. Verani, Bioinorg. Chem. Appl., 2006, 1-12.

15 E.J. U. Pérez, M.C. Aragoni, M. Arca, A.J. Blake, F.A. Devillanova, A. Garau, F. Isaia, V. Lippolis, R. Núñez, A. Pintus and C. Wilson, 2011, 17, Chem. Eur. J., 11497-11514.

16 D. J. Williams, D. Vanderveer, B. R. Crouse, R. R. Raye, T. Carter, K. S. Hagen and M. Brewer, Main Group Chem., 1997, 2, 61-66.

17 (a) M. Saab, D. J. Nelson, N. V. Tzouras, T. A. C. A. Bayrakdar, S. P. Nolan, F. Nahra and K. Van Hecke, Dalton Trans., 2020 49, 12068-12081; (b) F. Nahra, K. Van Hecke, A. R. Kennedy and D. J. Nelson, Dalton Trans., 2018, 47, 10671-10684; (c) D. J. Nelson, F. Nahra, S. R. Patrick, D. B. Cordes, A. M. Z. Slawin and S. P. Nolan, Organometallics, 2014, 33, 3640-3645; (d) D. J. Nelson, A. Collado, S. Manzini, S. Meiries, A. M. Z. Slawin, D. B. Cordes and S. P. Nolan, Organometallics, 2014, 33, 20482058; (e) S. V. C. Vummaleti, D. J. Nelson, A. Poater, A. GomezSuarez, D. B. Cordes, A. M. Z. Slawin, S. P. Nolan and L. Cavallo, Chem. Sci., 2015, 6, 1895-1904.

18 (a) A. Liske, K. Verlinden, H. Buhl, K. Schaper and C. Ganter, Organometallics, 2013, 32, 5269-5272; (b) K. Verlinden, H. Buhl, W. Frank and C. Ganter, Eur. J. Inorg. Chem., 2015, 2015, 2416-2425.

19 (a) L. M. Bouchet, A. B. Pierini, V. Brunetti and J. E. Argüello, J. Phys. Org. Chem., 2016, 29, 620-628; (b) J. Beerhues, M. Neubrand, S. Sobottka, N. I. Neuman, H. Aberhan, S. Chandra and B. Sarkar, Chem. Eur. J., 2021, 27, 6557; (c) B. Mishra, D. K. Maity, K. I. Priyadarsini, H. Mohan and J. P. Mittal, J. Phys. Chem. A, 2004, 108, 1552-1559.

20 M. M. Kimani, D. Watts, L. A. Graham, D. Rabinovich, G. P. A. Yap and J. L. Brumaghim, Dalton Trans., 2015, 44, 16313.

21 L. Koskinen, S. Jääskeläinen, P. Hirva and M. Haukka, Cryst. Growth Des., 2015, 15, 1160-1167.

22 J. L. Dutton, R. Tabeshi, M. C. Jennings, A. J. Lough and P. J. Ragogna, Inorg. Chem., 2007, 46, 8594-8602.

23 F. A. Devillanova, P. Deplano, F. Isaia, V. Lippolis, M. L. Mercuri, S. Piludu, G. Veran and F. Demartin, Polyhedron, 1998, 17, 305-312.

24 (a) F. Freeman, J. W. Zi1ler, H. N. Po and M. C. Keindl, J. Am Chem. Soc., 1988, 110, 2586; (b) F. V. Bolhuis, P. B. Koster and T. Migchelsen, Acta Crystallogr., 1967, 23, 90.

25 S. T. Manjare, S. Sharma, H. B. Singh and R. J. Butcher, J. Organomet. Chem., 2012, 717, 61-74. 